\title{
A New Nerve Growth Factor-Mimetic Peptide Active on Neuropathic Pain in Rats
}

\author{
Anna Maria Colangelo, ${ }^{1 *}$ Maria Rosaria Bianco, ${ }^{2 *}$ Luigi Vitagliano, ${ }^{3 *}$ Carlo Cavaliere, ${ }^{2}$ Giovanni Cirillo, ${ }^{2}$ \\ Luca De Gioia, ${ }^{1}$ Donatella Diana, ${ }^{3}$ Daniele Colombo, ${ }^{1}$ Cristina Redaelli, ${ }^{1}$ Laura Zaccaro, ${ }^{3}$ Giancarlo Morelli, ${ }^{3}$ \\ Michele Papa, ${ }^{2}$ Paolo Sarmientos, ${ }^{4}$ Lilia Alberghina, ${ }^{1}$ and Enzo Martegani ${ }^{1}$ \\ ${ }^{1}$ Laboratorio di Neuroscienze "R. Levi-Montalcini" and Dipartimento di Biotecnologie e Bioscienze, Università di Milano-Bicocca, 20126 Milan, Italy, \\ ${ }^{2}$ Laboratorio di Morfologia delle Reti Neuronali, Dipartimento di Medicina Pubblica Clinica e Preventiva, Seconda Università di Napoli, 80138 Naples, Italy, \\ ${ }^{3}$ Centro Interuniversitario di Ricerca sui Peptidi Bioattivi and Dipartimento delle Scienze Biologiche, Università di Napoli “Federico II" and Istituto di \\ Biostrutture e Bioimmagini, Consiglio Nazionale delle Ricerche, 80138 Naples, Italy, and ${ }^{4}$ Primm srl, 20132 Milan, Italy
}

\begin{abstract}
Analysis of the structure of nerve growth factor (NGF)-tyrosine kinase receptor A (TrkA) complex, site-directed mutagenesis studies and results from chemical modification of amino acid residues have identified loop 1, loop 4, and the N-terminal region of the NGF molecule as the most relevant for its biological activity. We synthesized several peptides mimicking the two loops (1 and 4) linked together with an appropriate spacer, with or without the N-terminal region. Two peptides named NL1L4 and L1L4 demonstrated good NGF agonist activity at a concentration as low as $3 \mu \mathrm{m}$. They induced differentiation of chick dorsal root ganglia and stimulated tyrosine phosphorylation of TrkA, but not TrkB, receptor. In addition L1L4 was able to induce differentiation of PC12 cells. More interestingly, the peptide with the highest "in vitro" activity (L1L4) was shown to reduce neuropathic behavior and restore neuronal function in a rat model of peripheral neuropathic pain, thereby suggesting a potential therapeutic role for this NGF-mimetic peptide.
\end{abstract}

Key words: NGF; bioactive peptides; NMR structure; neuropathic pain; gliosis; TrkA

\section{Introduction}

Nerve growth factor (NGF) plays a crucial role in neuronal survival, differentiation and growth (Levi-Montalcini, 1987). NGF is a homodimeric protein that binds two distinct cellular receptors: the tyrosine kinase receptor TrkA and the p75 receptor (Chao, 2003). Interestingly, the activation of these receptors produces different responses. Activation of TrkA mediates neuronal survival and differentiation, whereas p75 activation can induce apoptosis (Chao, 2003). As found for other tyrosine kinase receptors, the dimeric NGF protein induces TrkA dimerization, which leads to the autophosphorylation of the receptor and activation of signaling pathways (Huang and Reichardt, 2003).

The potential of NGF as a therapeutic agent for several diseases including neurodegenerative disorders, inflammation and certain types of cancers has been indicated by several investigators (Apfel, 2002; Aloe and Calzà, 2004; Williams et al., 2006). However, the use of NGF for the treatment of these pathologies

\footnotetext{
Received June 6, 2007; revised Jan. 8, 2008; accepted Jan. 8, 2008.

This work was supported in part by Associazione Levi-Montalcini and by the following research grants from Ministery of University and Research: Fondo Integrativo Speciale per la Ricerca (CU 03.00145) to L.A., Programma Nazionale della Ricerca (legge 287) to Primm, and Fondo Investimenti Ricerca di Base (RBNE03PX83) to Istituto di Biostrutture e Bioimmagini.

${ }^{*}$ A.M.C., M.R.B., and L.V. contributed equally to this work.

Correspondence should be addressed to either of the following: Enzo Martegani, Dipartimento di Biotecnologie e Bioscienze, Università di Milano-Bicocca, Piazza della Scienza 2, 20126 Milan, Italy, E-mail: enzo.martegani@unimib.it; or Paolo Sarmientos, Primm srl, Via Olgettina 58, 20132 Milan, Italy, E-mail: paolo.sarmientos@primm.it.

DOI:10.1523/JNEUROSCI.5201-07.2008

Copyright $\odot 2008$ Society for Neuroscience $\quad 0270-6474 / 08 / 282698-12 \$ 15.00 / 0$
}

has been limited by the poor pharmacological properties of this protein, such as the low blood-brain barrier permeability (Poduslo and Curran, 1996) and relevant side effects, like hyperalgesia (Apfel, 2002). Development of small molecules with NGFagonist activity, with better pharmacokinetics, and less side effects, is therefore of high interest. To achieve this goal, different approaches based on both natural and synthetic products have been attempted (Longo et al., 1997; Maliartchouk et al., 2000a,b; Peleshok and Saragovi, 2006).

Particularly attractive is the search for small molecules that bind to selective receptors and mimic or antagonize the activity of NGF. Many efforts have been devoted to design mimetics using NGF fragments. Crystallographic and molecular modeling studies of NGF/TrkA complexes (McDonald et al., 1991; McDonald and Chao, 1995; Urfer et al., 1998; Wiesmann et al., 1999), mutagenesis analysis (Ibànez et al., 1992; Kahle et al., 1992; Drinkwater et al., 1993; Shih et al., 1994; Woo et al., 1995; Krüttgen et al., 1997; Kullander et al., 1997; Rydén and Ibàñez, 1997), and chemical modification of specific amino acids (Bradshaw et al., 1994; McDonald and Chao, 1995) have indicated the hydrophilic loops 1 and 4 and the N-terminal region of NGF as the most relevant for its biological activity. Among various peptides reported in the literature, linear peptides showed inhibitory, but no agonist activity (Longo et al., 1990), and cyclic peptides corresponding to the loop 1 sequence were shown later to have a 10-fold higher inhibitory activity (LeSauteur et al., 1995). The first NGF loop domain peptides described to have neurotrophic activity were the loop 1 homodimer mimetics described by Longo 
et al. (1997). Subsequent studies (Maliartchouk et al., 2000a,b; Xie et al., 2000) described loop 4 mimetics with agonist activity.

The low efficacy of these compounds led us to use a different approach based on the combination of different NGF regions in the same molecule. The resulting peptides showed a good NGFlike activity in vitro by inducing differentiation of dorsal root ganglia (DRGs), TrkA phosphorylation, and differentiation of PC12 cells. Moreover, the peptide with the highest "in vitro" activity (L1L4) resulted effective in reducing neuropathic pain in an animal model.

\section{Materials and Methods}

Design of NGF agonists by molecular modeling. The identification of the regions that mediate NGF-TrkA interactions was performed by molecular graphics using the $\mathrm{x}$-ray structure of the complex of NGF with the second immunoglobulin-like TrkA domain (d5-trkA) (Protein Data Bank code 1WWW) (Wiesmann et al., 1999). The occurrence of NGF structural modifications induced by the binding of the receptor was performed using the structure of the unligated form of NGF (Protein Data Bank code 1BET) (McDonald et al., 1991) as a reference. The conformational properties of the designed peptides were evaluated by molecular mechanics and molecular dynamics calculations using the InsightII/Discover package (Biosym/MSI, San Diego, CA). Human and mouse $\beta$-NGF sequences were obtained from Swissprot (P01138 and P01139, respectively).

Antibodies and drugs. Polyclonal rabbit anti-Trk IgG (C-14) raised against the highly conserved C-terminus of TrkA and antiphosphotyrosine mAb (PY99) were purchased from Santa Cruz Biotechnology (Santa Cruz, CA). HRP-conjugated donkey anti-rabbit and antimouse IgGs were obtained from Jackson ImmunoResearch (West Grove, PA).

Polyclonal rabbit antibodies directed to Substance P (Sub P; S1542; Sigma, St. Louis, MO), polyclonal rabbit antibodies directed to Calcitonine gene-related peptide (CGRP; AB1971; Millipore, Billerica, MA), polyclonal rabbit antibodies directed to calbindin D-28k (Cb; CB-38; Swant, Bellinzona, Switzerland), monoclonal mouse antibodies directed to glial fibrillary acidic protein (GFAP; G3893; Sigma), and monoclonal rat antibodies directed to the rat homolog of human CD68 (ED1; MCA341R; Serotec, Raleigh, NC) were used for immunohistochemistry.

Murine 2.5 S NGF (mNGF) purified from male mouse submaxillary glands and recombinant human brain-derived neurotrophic factor (rhBDNF) were purchased from Promega (Madison, WI), whereas rat recombinant $\beta$-NGF was from Sigma. The cell-permeable tyrosine kinase inhibitor K-252a was obtained from Calbiochem (La Jolla, CA).

Synthesis of peptides. The linear precursors of all peptides were obtained by using the automatic synthesizer Syro (MultiSynTech, Witten, Germany). A small synthesis scale $(0.030 \mathrm{mmol})$ was used to prepare the peptides for in vitro experiments, whereas a larger scale $(1.0 \mathrm{mmol})$ was used to obtain the peptides studied in vivo.

All peptides were synthesized using 9-fluorenylmethoxycarbonyl (Fmoc) solid phase strategy followed by disulphide bridge formation in solution. S-Trt (Trityl) protecting group was used for the peptides containing a single disulfide bridge (AcL1, AcL4, SSL1L4, and L1SSL4). The same protecting group was used for cysteine derivatives belonging to loop 1 in peptides containing two loops in the cyclized form. S-Acm (acetamidomethyl) group was used to selectively protect cysteine residues belonging to the sequence mimicking loop 4 in peptides containing both loops.

Syntheses of AcNL1L4, NL1L4, AcL1L4, L1L4 L1L4(E), L1L1, and L4L4 linear precursors were performed with Fmoc-Cys(Acm)-Wang resin. AcL1 and AcL4 were synthesized by using Fmoc-Thr(t-Bu) polystyrene (PS)-polyhydroxybutyrate (PHB) and Fmoc-Cys(Trt) PS-PHB resins, respectively. Syntheses of L1SSL4 and SSL1L4 were performed by Fmoc-Ser(tBu)-Wang and Fmoc-Cys(Trt)-Wang resins, respectively. Cys preloaded resin were used to reduce the racemization level because of the esterification of protected cysteine residue onto the resin.

Fmoc deprotection reactions were performed with $30 \%$ piperidine in $\mathrm{N}, \mathrm{N}$-dimethylformamide (DMF) and active ester coupling reactions were performed using HBTU (2-(1H-benzotriazol-1-yl)-1,1,3,3tetramethyluronium hexafluorophosphate, 4 equivalents)/HOBt (1hydroxybenzotriazole, 4 equivalents) as coupling reagent and $\mathrm{N}, \mathrm{N}$ diiopropylethylamine (DIPEA) (eight equivalents) in DMF. At the end of the synthesis and before the cleavage/deprotection step, the peptides AcL1, AcL4, AcL1L4, and AcNL1L4 were acetylated on the resin by using a solution of $0.5 \mathrm{M}$ acetic anhydride, $0.125 \mathrm{M}$ DIPEA and $0.015 \mathrm{M} \mathrm{HOBt}$ in DMF.

The peptides were cleaved off the resin with the simultaneous deprotection of all side chain protecting groups, except for the Acm on the thiol function, by using a mixture of trifluoroacetic acid (TFA) $/ \mathrm{H}_{2} \mathrm{O} /$ phenol/ thioanisole/EDT (1,2-ethanedithiol)/TIS (triisopropylsilane) (81.5:5:5: $5: 2.5: 1 \mathrm{v} / \mathrm{v} / \mathrm{v} / \mathrm{v} / \mathrm{v} / \mathrm{v})$. The resins were then filtered off and crude products were precipitated using ethyl ether.

The crude products, with free thiol function on cysteine belonging to loop 1, but with cysteine residues belonging to loop 4 still bearing the Acm TFA-resistant protecting group, were purified by preparative HPLC. Identity of the purified peptides was confirmed by matrix-assisted laser desorption ionization (MALDI) mass spectrometry on a MALDItof Voyager-DE (Perseptive Biosystem, Framingham, MA) spectrometer.

Purity of the peptides was assessed in the range of $90-95 \%$ by analytical HPLC.

The formation of the first disulphide bridge of AcL1L4, L1L4, AcNL1L4, NL1L4, L1L4(E), L1L1 and L4L4, and the monodisulphide bridge of the other sequences were performed in the presence of atmospheric oxygen at high dilution $(0.1 \mathrm{~mm})$ in phosphate buffer at $\mathrm{pH} 7-8$ for $24 \mathrm{~h}$. Reactions were monitored by RP-HPLC. The second oxidation reaction to obtain the disulphide bridge Cys ${ }^{12}-\mathrm{Cys}{ }^{17}$ of AcL1L4, L1L4, L1L4(E), Cys ${ }^{12}$-Cys ${ }^{19}$ of L1L1, Cys ${ }^{10}-$ Cys ${ }^{15}$ of L4L4, and Cys ${ }^{33}-$ Cys ${ }^{38}$ of AcNL1L4 and NL1L4 was performed by iodine-mediated oxidation. The S-Acm deprotection/oxidation step was performed at high dilution $(0.1 \mathrm{~mm})$ in acetic acid/ $\mathrm{H}_{2} \mathrm{O}(1: 1)$ in the presence of iodine (10 equivalents) for $30 \mathrm{~min}$. The rate of the oxidations was followed by RP-HPLC: the appearance of side products, after $30 \mathrm{~min}$, suggested stopping the reaction despite the fact that a sensible percentage of linear precursor was still unreacted. The iodine excess was quenched by sodium thiosulphate.

Final purification of cyclic peptides was performed by HPLC. Overall yields of the purified peptides, calculated as percent of the theoretical expected quantities, were in the range of $10-20 \%$ for peptides containing a single disulfide bridge, and $<5 \%$ for peptides containing both loops in the cyclized form.

NMR spectroscopy measurements and structure calculation. Nuclear magnetic resonance (NMR) samples were prepared by dissolving the L1L4 peptide at a concentration of $1.0 \times 10^{-3} \mathrm{M}$ in a $\mathrm{H}_{2} \mathrm{O} /{ }^{2} \mathrm{H}_{2} \mathrm{O} 90: 10$ mixture at $\mathrm{pH}$ 5.3. NMR experiments were recorded on a Varian (Palo Alto, CA) Inova 600 spectrometer at a temperature of $298 \mathrm{~K}$. Water suppression was accomplished by using double-pulsed field gradient spin echo. Total correlation spectroscopy (TOCSY) (Griesinger et al., 1988) and nuclear Overhauser enhancement spectroscopy (NOESY) (Kumar et al., 1980) spectra were acquired with mixing times of 70 and $250 \mathrm{~ms}$, respectively. Double quantum-filtered (DQF) spectrum [DQFcorrelation spectroscopy (COSY)] (Rance et al., 1983) was recorded with 4096 data points in the direct dimension and with 500 increments each comprising 64 scans to obtain enough resolution to measure the ${ }^{3} \mathrm{~J}_{\mathrm{HNH} \alpha}$ coupling constants. All spectra were processed with the software PROSA (Guntert et al., 1992) and analyzed with the program Xeasy (Bartels et al., 1995).

Experimental distance restraints for structure calculations were derived from the cross-peak intensities in NOESY spectra. Distance constraints together with 14 scalar coupling constants $\left({ }^{3} \mathrm{~J}_{\mathrm{HNH} \alpha}\right)$ were then used by the grid search module, implemented in CYANA (Herrmann et al., 2000), to generate a set of allowable dihedral angles.

In total, 150 NOE cross peaks were assigned and integrated; stereospecific assignment for Cys8 and Lys $15\left(\beta \mathrm{CH}_{2}\right.$ protons) was derived from the input data using the software CYANA. The final input file for the CYANA structure calculation software contained 102 meaningful distance constraints ( 37 intraresidue, 46 short range, and 13 medium range) and 49 angle constraints, which were derived from intraresidue and se- 
quential NOEs and the ${ }^{3} \mathrm{~J}_{\mathrm{HNH} \alpha}$ coupling constants. Structure calculations, which used the torsion angle dynamics protocol of CYANA, were then started from 100 randomized conformers. The 20 conformers with the lowest CYANA target function were further refined by means of restrained energy minimization, using the Gromos 96 force field, with the program SPDB Viewer (Guex and Peitsch, 1997).

Cell cultures. PC12 cells (clone 615) (Hempstead et al., 1992) stably overexpressing TrkA (kindly provided by M. V. Chao, Skirball Institute, New York University School of Medicine, New York, NY) were maintained in DMEM (Sigma) supplemented with 5\% fetal bovine serum (FBS; Sigma), 10\% heat-inactivated horse serum (HS; Sigma), 2 mm L-glutamine, 100 $\mu \mathrm{g} / \mathrm{ml}$ streptomycin, $100 \mathrm{U} / \mathrm{ml}$ penicillin, and $200 \mu \mathrm{g} / \mathrm{ml} \mathrm{G} 418$ (Sigma), in a humidified atmosphere of $95 \%$ air $5 \% \mathrm{CO}_{2}$ at $37^{\circ} \mathrm{C}$ as described previously (Colangelo et al., 2005). Treatments of PC12 cells were performed in DMEM supplemented with $0.5 \%$ FBS and $1 \%$ heat-inactivated HS. Differentiation was measured as percentage of cells bearing neurite processes whose length was at least three times the diameter of cell body.

DRGs were dissected from 8-d-old chick embryos and placed into HEPES buffered saline solution. Ganglia were then cultured onto polyL-lysine (1\%) precoated dishes in DMEM supplemented with $10 \% \mathrm{FBS}, 2 \mathrm{~mm}$ L-glutamine, $100 \mu \mathrm{g} / \mathrm{ml}$ streptomycin, and $100 \mathrm{U} / \mathrm{ml}$ penicillin. Treatments with peptides or $2.5 \mathrm{~S}$ mNGF (Promega) were performed immediately after plating and explants were monitored for $7-10 \mathrm{~d}$ under a reversed microscope equipped with an Olympus (Tokyo, Japan) camera.

Cerebellar granule cells were prepared from 8-d-old Sprague Dawley rat pups (Harlan Italy, San Pietro de Natisone, Italy) as described previously (Marini et al., 1998). Briefly, cerebella were minced in KrebsRinger bicarbonate solution and dissociated with $0.025 \%$ trypsin for 20 min at $37^{\circ} \mathrm{C}$ followed by trituration with a Pasteur pipette. Cells were plated onto poly-L-lysine coated dishes $\left(2 \times 10^{7}\right.$ cells/dish $)$ in basal Eagle's medium (Sigma) containing 10\% FBS, 2 mm L-glutamine, $25 \mathrm{~mm}$ potassium chloride, $100 \mathrm{U} / \mathrm{ml}$ penicillin, $100 \mu \mathrm{g} / \mathrm{ml}$ streptomycin, and 50 $\mu \mathrm{g} / \mathrm{ml}$ gentamicin (Sigma). Cytosine arabinoside (10 $\mu \mathrm{M}$; Sigma) was added to the culture medium after $18-24 \mathrm{~h}$ to inhibit the proliferation of non-neuronal cells. Granule neurons were supplied with glucose (5 mM) on day in vitro (DIV) 7 and used for the experiments on DIV 9.

Tyrosine phosphorylation of Trk receptors. Immunoblotting analysis of Trk phosphorylation in PC12 cells and cerebellar granule neurons was performed as described previously (Colangelo et al., 2005). Briefly, cells were exposed for $10 \mathrm{~min}$ to medium alone, NGF-like peptides, $2.5 \mathrm{~S}$ mNGF, or rhBDNF, washed, and lysed at $4^{\circ} \mathrm{C}$ in $1 \mathrm{ml}$ of radioimmunoprecipitation assay (RIPA) buffer ( $50 \mathrm{~mm}$ Tris, $\mathrm{pH} 7.5,150 \mathrm{~mm} \mathrm{NaCl}, 1 \%$ Nonidet P-40, $0.5 \%$ sodium deoxycholate, $0.1 \%$ SDS $/ 1$ mm DTT) containing protease inhibitors (2 mM PMSF, $1 \mu \mathrm{g} / \mathrm{ml}$ leupeptin, $5 \mu \mathrm{g} / \mathrm{ml}$ aprotinin) and phosphatase inhibitors (5 $\mathrm{mm} \mathrm{NaF}$ and $1 \mathrm{~mm}$ sodium orthovanadate). Lysates (200 $\mu \mathrm{g}$ of total proteins) were incubated overnight at $4^{\circ} \mathrm{C}$ with $2 \mu \mathrm{g}$ of anti-pan-trk IgG (C-14; Santa Cruz Biotechnology) followed by precipitation with protein A-Sepharose (Sigma) for additional $2 \mathrm{~h}$ at $4^{\circ} \mathrm{C}$. After washing in RIPA buffer, immunocomplexes were resuspended in $20 \mu \mathrm{l}$ of loading buffer ( $2 \%$ SDS/100 mM DTT/10\% glycerol $/ 0.2 \%$ bromophenol blue), separated on $7.5 \%$ SDS-PAGE, and transferred to nitrocellulose (Whatman, Dassel, Germany). After blocking with 5\% nonfat milk in TBST buffer (10 mM Tris pH 7.5/150 mM $\mathrm{NaCl} / 0.2 \%$ Tween 20 ), blots were probed overnight at $4^{\circ} \mathrm{C}$ with anti-pTyr mAb (PY99, 1:1000; Santa Cruz Biotechnology) in TBST, followed by incubation with HRP-conjugated donkey anti-mouse IgG (1:10,000; Jackson ImmunoResearch) for $1 \mathrm{~h}$ at room temperature (RT). Detection of phosphorylated species was performed by using the enhanced chemiluminescence (ECL) system (GE Healthcare Bio-Sciences, Piscataway, NJ).

Animals. Adult (250-300 g; Charles River, Calco, Italy) male Sprague Dawley rats were used. Experiments were performed according to a protocol approved by the animal care committee of the Italian Ministry of Public Health and in accordance with guidelines of the National Institutes of Health Guide for the Care and Use of Laboratory Animals. Rats were maintained on a $12 \mathrm{~h}$ light/dark cycle and were allowed access to food and water ad libitum. Each animal was housed under specific pathogen-free conditions in iron sheet cages with solid floors covered with $4-6 \mathrm{~cm}$ of soft bedding (sawdust) during the experiments. Cages with thin plate floors were avoided on the assumption that they would exacerbate discomfort arising from the affected hind paw. Thirty-six rats were divided into eight groups of five rats each for different treatment analysis (Bai et al., 1999).

Chronic sciatic constriction injury model. Rats were anesthetized by intraperitoneal chlorydrate tiletamine $(40 \mathrm{mg} / \mathrm{kg}$ body weight $)$ during surgery. The common sciatic nerve of the right hindlimb was exposed at the level of the thigh. In treated animals $(n=30)$, proximal to the sciatic nerve trifurcation, three ligatures were tied loosely around it with 3-0 gut. Intervals between the ligatures were $1 \mathrm{~mm}$, so that the length of the treated nerve was $\sim 3-4 \mathrm{~mm}$ (Bennet and Xie, 1998). These treatments were performed by microsurgical techniques; great care was taken in tying the ligatures, and the nerve was seen to be barely constricted when viewed at $40 \times$ magnification. The desired degree of constriction retarded, but did not arrest, circulation through the superficial epineurial vasculature and sometimes produced a small, brief twitch in the muscles surrounding the exposure. The wound was irrigated with saline and closed in two layers with 3-0 silk (fascial plane) and surgical skin staples. On the remaining animals $(n=6)$, sham surgery was performed without ligatures, and these animals were used as controls. 

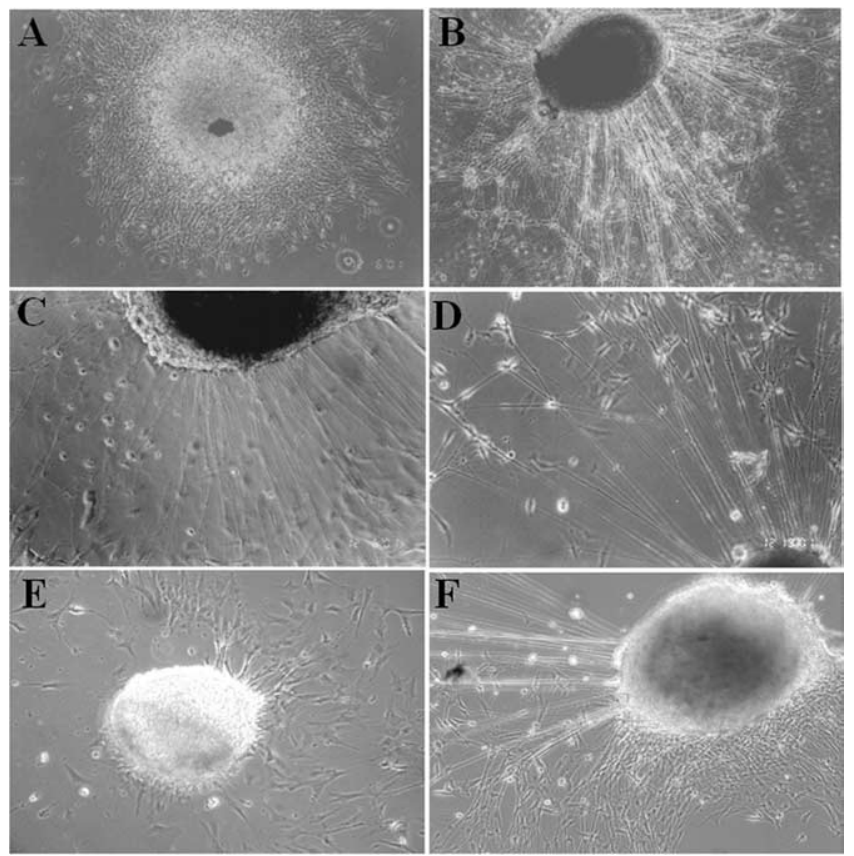

Figure 1. Differentiation of DRGs induced by bicyclic NGF-like molecules. $A-F$, Representative images of DRGs dissected from 8-d-old chick embryos and cultured for $3 \mathrm{~d}$ in complete culture medium alone $(\boldsymbol{A})$, or medium containing the peptides NL1L4 cyclic ( 3 and $10 \mu \mathrm{m}$; $C$ and $\boldsymbol{D}$, respectively) or linear $(10 \mu \mathrm{m} ; \boldsymbol{E})$, or L1L4 $(3 \mu \mathrm{m} ; \boldsymbol{F})$. In $\boldsymbol{B}$, ganglia were maintained in the presence of $2.5 \mathrm{~S} \mathrm{mNGF}(5 \mathrm{ng} / \mathrm{ml}$, corresponding to $0.192 \mathrm{~nm})$. Treatments were performed $3 \mathrm{~h}$ after plating and repeated every other day after changing the culture medium for $\sim 2$ weeks. Differentiation of ganglia was monitored and recorded under a reversed microscope Olympus CX40 (20 $\times)$ equipped with an Olympus camera.

Drug delivery. To reduce the bias in behavioral analysis of discomfort caused by lumbar spinal catheter, the chronic intrathecal lumbar spinal catheter was positioned the same day as chronic sciatic constriction injury (CCI), according to the method described previously (Coderre, 1992). Briefly, a small opening was made at the laminas of the lumbar tract of the spine and a catheter [polyethylene (PE) 10 tubing attached to PE 60 tubing for connection to an osmotic pump] was inserted into the subarachnoid space and directed to the lumbar enlargement of the spinal cord. After anchoring the catheter across the careful apposition of a glass ionomer luting cement triple pack (Ketac Cem radiopaque; 3M ESPE, Seefeld, Germany), the wound was irrigated with saline and closed in two layers with 3-0 silk (fascial plane) and surgical skin staples. On recovery from surgery, lower body paralysis was induced by intrathecal lidocaine $(2 \%, 30 \mu \mathrm{l})$ injection to confirm proper catheter localization. Each rat was placed on a table, and the gait and posture of the affected hind paw were carefully observed for $2 \mathrm{~min}$. Only animals exhibiting appropriate, transient paralysis to lidocaine, as well as a lack of motor deficits, were used for treatments [ $\beta$-NGF, $n=10$; L1L4 peptide, $n=10$; or artificial CSF (ACSF) infusion, $n=10$ ] and behavioral testing.

Seven day neuropathic rats were anesthetized by intraperitoneal chlorohydrate tiletamine $(40 \mathrm{mg} / \mathrm{kg})$, the free extremity of the catheter was connected to an osmotic minipump, and the pump was implanted subcutaneously.

Osmotic pumps attached to intrathecal lumbar spinal catheters were filled with either $37.5 \mu \mathrm{g} / \mu \mathrm{l}$ of L1L4 NGF-like peptide or $125 \mathrm{ng} / \mu \mathrm{l}$ rat recombinant $\beta$-NGF (Sigma) in a solution of ACSF containing $1 \mathrm{mg} / \mathrm{ml}$ rat serum albumin (Sigma), or vehicle only (ACSF). The osmotic pumps were model 2001 Alzet (Cupertino, CA) pumps, which pumped at a rate of $1 \mu \mathrm{l} / \mathrm{h}$ for $7 \mathrm{~d}$. This rate produced an intrathecal infusion dose of 37.5 $\mu \mathrm{g} / \mathrm{h}$ of L1L4 peptide or $125 \mathrm{ng} / \mathrm{h}$ of NGF.

Behavioral testing. Animals were accustomed to the testing environment daily for at least $2 \mathrm{~d}$ before baseline testing. Both the experimental groups that underwent CCI surgery followed by treatment with L1L4 peptide (L1L4 group), $\beta$-NGF (NGF group), or vehicle only (ACSF
A

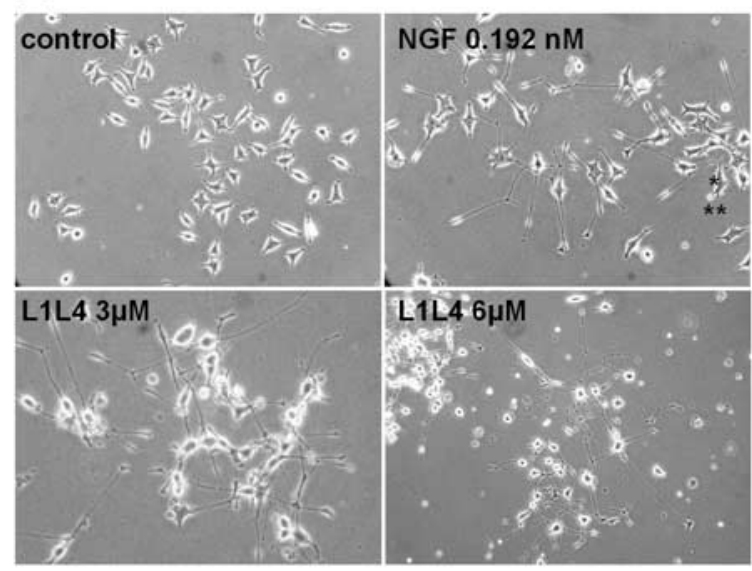

B

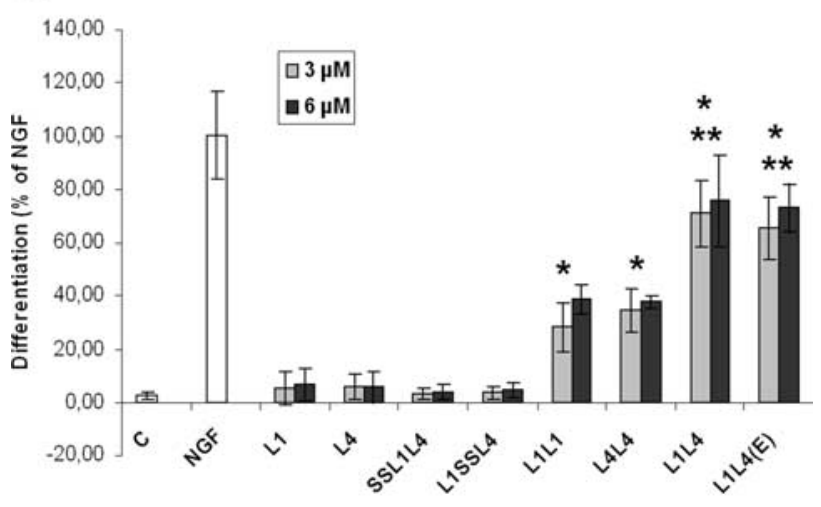

C

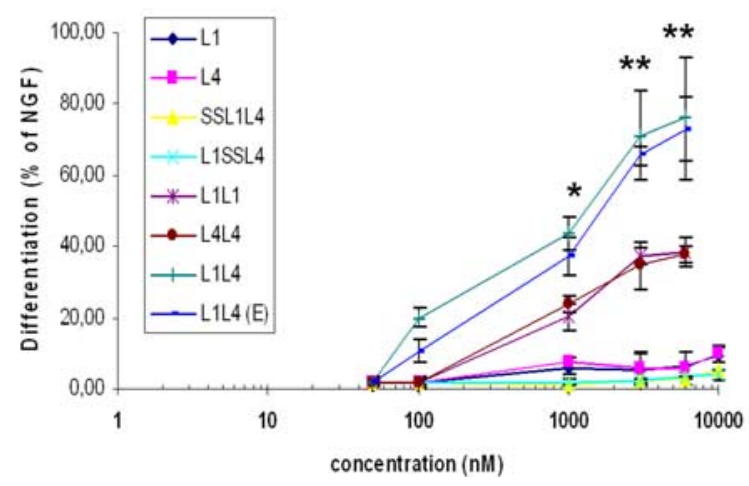

Figure 2. Induction of $\mathrm{P}(12$ cells differentiation by bicyclic NGF-like molecules. $A$, Representative images of $\mathrm{PC} 12$ (615) cells differentiated for 3 din the presence of $\mathrm{L} 1 \mathrm{~L} 4$ ( 3 and $6 \mu \mathrm{M}$ ) or 2.5 $\mathrm{S}$ mNGF $(0.192 \mathrm{~nm})$. Treatments were performed under reduced serum conditions $(0.5 \% \mathrm{FBS}$ and $1 \% \mathrm{HS}$ ). $\boldsymbol{B}$, Differentiation levels induced after $3 \mathrm{~d}$ of treatment with single cycle ( $\mathrm{L} 1, \mathrm{~L} 4$, SSL1L4, and L1SSL4), homodimers (L1L1 and L4L4), and bicyclic peptides (L1L4 and L1L4(E) at 3 and $6 \mu \mathrm{m}$. C, Dose-response studies of the same molecules (50-100 nm and 1, 3, 6, and 10 $\mu \mathrm{M}$ ). In $\boldsymbol{B}$ and $\boldsymbol{C}$, data are expressed as percentage of the differentiation (cells with neurite processes at least 3 times the diameter of cell body) induced by $2.5 \mathrm{SmNGF}(0.192 \mathrm{nM})$. Data are the mean \pm SEM of at least three experiments, each in duplicate. ${ }^{*} p<0.05$, L1L 4 and L1L4(E) $3 \mu \mathrm{m}$ versus NGF; L1L4 $(1 \mu \mathrm{m})$ versus L1L1 and L4L4 $(1 \mu \mathrm{M}) .{ }^{* *} p<0.01$, L1L4 and L1L4(E) (3 $\mu \mathrm{M}$ ) versus L1, L4, SSL1L4, L1SSL4, L1L1, and L4L4 (3 $\mu \mathrm{M}) ;$ L1L1 and L4L4 versus L1 and L4, respectively (ANOVA and Dunnett's test).

group), and the sham-operated animals [control (CTR) group] were behaviorally tested according to this time schedule: on day 0 (the day of the CCI and i.t. lumbar spinal catheter positioning), on day 7 (7 d after surgery), on day 14 ( $7 \mathrm{~d}$ after implant of the pump)]. On day 14, all animals were killed. 


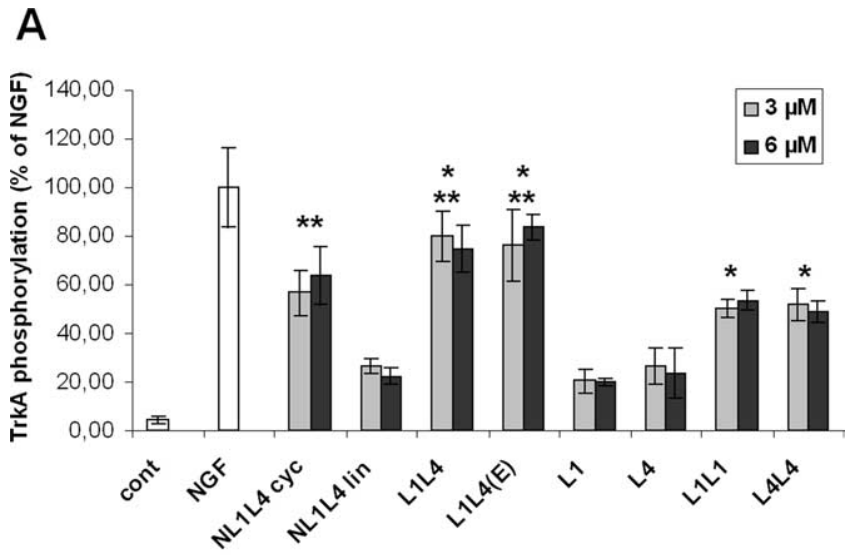

B

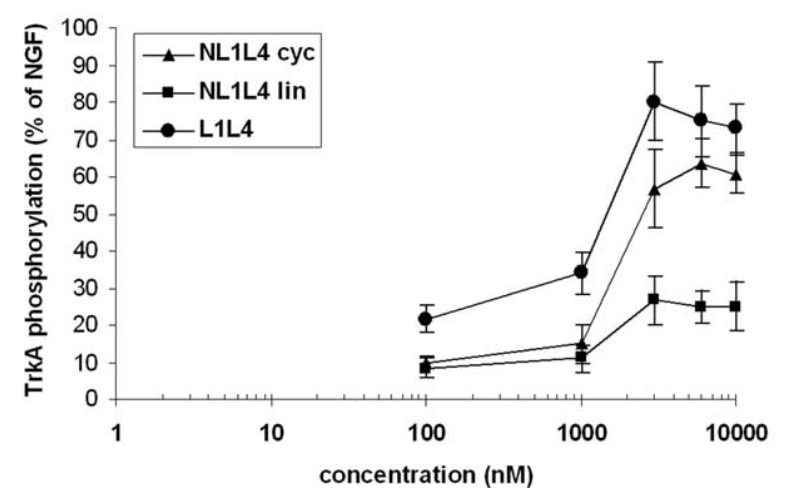

Figure 3. Levels of TrkA phosphorylation induced by NGF-like molecules. A, Analysis of TrkA phosphorylation levels in PC12(615) cells after 10 min incubation with mNGF (0.192 nM), or NL1L4 (cyclic and linear), L1L4, L1L4(E), L1, L4, L1L4, and L4L4, each at 3 or $6 \mu \mathrm{m}$, in low serum medium $(0.5 \% \mathrm{FBS}$ and $1 \% \mathrm{HS})$. Total proteins $(200 \mu \mathrm{g})$ were immunoprecipitated with the anti-pan-Trk antibody (C-14) and $\mathrm{p}$-TrkA was detected by probing the membrane with the anti-p-Tyr (PY-99). B, Dose-response (0.1-10 $\mu \mathrm{M}$ ) of L1L4 and NL1L4 (cyclic and linear). Data, expressed as percentage of TrkA phosphorylation induced by mNGF $(0.192 \mathrm{nM})$, are the mean \pm SEM of at least three experiments. ${ }^{*} p<0.05$, L1L4 and L1L4(E) versus L1L 1 and L4L4; L1L 1 and $\mathrm{L} 4 \mathrm{~L} 4$ versus $\mathrm{L} 1$ and $\mathrm{L} 4$, respectively. ${ }^{*} p<0.01, \mathrm{~L} 1 \mathrm{~L} 4$ and $\mathrm{L} 1 \mathrm{~L} 4(\mathrm{E})$ versus $\mathrm{L} 1$ and $\mathrm{L} 4$; NL1L4 (cyclic) versus NL1L4 (linear) (ANOVA and Dunnett's test).

Mechanical response thresholds were quantified by measuring the hind paw withdrawal response to von Frey filament stimulation according to the method described by Chaplan et al. (1994). In brief, animals were placed in a Plexiglas box $\left(21 \times 16 \times 27 \mathrm{~cm}^{3}\right)$ with a wire grid bottom through which the von Frey filaments (Ugo Basile, Comerio, Italy) were applied to the plantar surface of the injured hind limb. Animals were allowed to accustom for $30 \mathrm{~min}$ before testing. Filaments were applied in either ascending or descending strength as necessary to determine the filament closest to the threshold of response. The time of response to a progressive force applied to hindpaw limb (30 g in $20 \mathrm{~s}$ ) was evaluated six times in injured hind limb at intervals of 5 min between stimulations. The threshold was taken as the lowest force that evoked a consistent brisk withdrawal response (Hargreaves et al., 1988). Withdrawal latencies from noxious heat were assessed using the plantar test as described previously (Hargreaves et al., 1988). Rats were placed in Plexiglas boxes positioned on a glass surface. Animals were allowed to habituate for $30 \mathrm{~min}$ before testing. Paw withdrawal latency in response to radiant heat (infrared) was measured using the plantar test apparatus (Ugo Basile). The heat source was positioned under the plantar surface of the affected hind paw and activated at a setting of 7.0. The digital timer connected to the heat source automatically recorded the response latency for paw withdrawal to the nearest $0.1 \mathrm{~s}$ The intensity of the infrared light beam was chosen to give baseline latencies of $\sim 15 \mathrm{~s}$ in control rats. A cutoff time of $20 \mathrm{~s}$ was imposed to prevent tissue damage. Injured hind
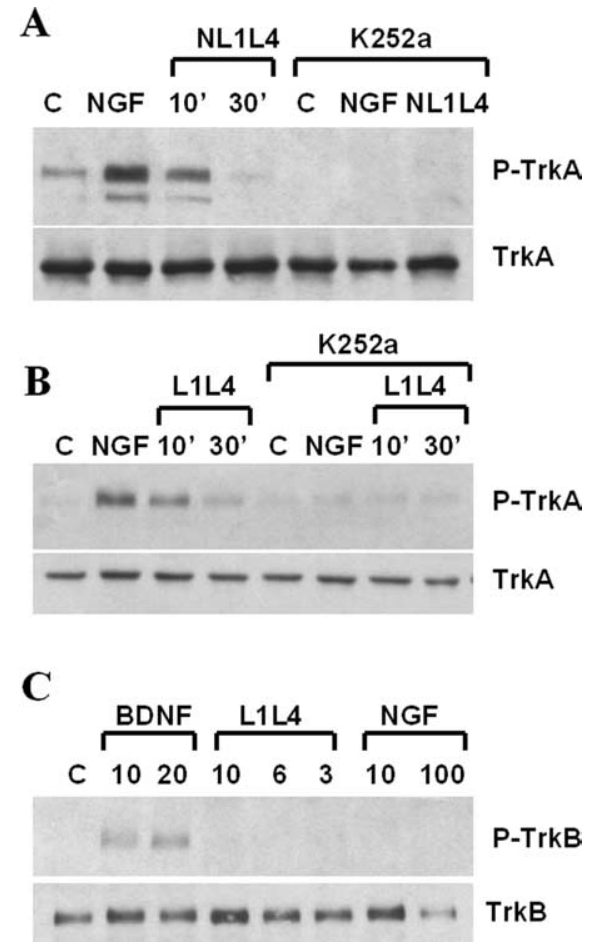

Figure 4. Characterization of Trk receptors interaction. $A, B$, Analysis of TrkA phosphorylation in PC12(615) cells exposed to mNGF (0.192 nM) or NL1L4 $(\boldsymbol{A})$ or L1L4 $(\boldsymbol{B})$, both at $3 \mu \mathrm{m}$, for 10 or $30 \mathrm{~min}$. Total proteins $(200 \mu \mathrm{g})$ were immunoprecipitated with the anti-pan-Trk antibody (C-14) and p-TrkA was detected by probing the membrane with the anti-p-Tyr (PY-99). Where indicated, cells were incubated with the cell-permeable tyrosine kinase inhibitor K252a (100 nM) for $10 \mathrm{~min}$ before addition of mNGF (0.192 nM) or NL1L4 or L1L4. C, Analysis of TrkB phosphorylation in cerebellar granule cells (at DIV 9) incubated for $10 \mathrm{~min}$ with rhBDNF (10 and 20 $\mathrm{ng} / \mathrm{ml})$ or L1L4 $(3,6$, and $10 \mu \mathrm{m})$. As a negative control, cells were left in medium alone or exposed to $\mathrm{mNGF}$ (10 and $100 \mathrm{ng} / \mathrm{ml}$ ). Lysates were immunoprecipitated with the anti-pan-Trk antibody (C-14) and blots were probed with anti-p-Tyr Ab (PY99). Blots were stripped and reprobed with anti-pan-Trk Ab to check for Trk protein content among samples (bottom).

limb was tested twice at each time point at intervals of 5 min between stimulations. All the testing was performed blinded.

Tissue preparation. Rats were deeply anesthetized by intraperitoneal injection $(300 \mathrm{mg} / \mathrm{kg}$ body weight) of chloral hydrate and perfused transcardially with saline solution ( $0.1 \mathrm{~m}$ TRIS-HCl/10 mM EDTA) followed by $4 \%$ paraformaldehyde added to $0.1 \%$ glutaraldehyde in $0.01 \mathrm{M}$ phosphate-buffer $(\mathrm{PB}), \mathrm{pH} 7.4$, at $4^{\circ} \mathrm{C}$. The spinal cord was removed and postfixed for $2 \mathrm{~h}$ in the same fixative, then soaked in 30\% sucrose in PBS and frozen in chilled isopentane on dry ice. Serial sections were cut on a cooled sliding microtome at a thickness of $25 \mu \mathrm{m}$ and collected in cold PBS for immunocytochemistry.

Immunocytochemistry. Spinal cord sections were blocked in 10\% normal serum in $0.01 \mathrm{~m}$ PBS/0,25\% Triton for $1 \mathrm{~h}$ at RT. Each primary antibody was diluted in $0.01 \mathrm{~m}$ PBS containing $10 \%$ normal serum and $0.25 \%$ Triton. Free floating slices were incubated for $48 \mathrm{~h}$ at $4^{\circ} \mathrm{C}$ on an oscillating plate. Sections were washed several times in PBS and incubated with the appropriate biotinylated secondary antibody (1:200; Vector Laboratories, Burlingame, CA) for $90 \mathrm{~min}$ at RT, washed in PBS and processed for 90 min at RT by using the Vectastain avidin-biotin peroxidase kit (Vector Laboratories). Sections were washed in $0.05 \mathrm{M}$ Tris- $\mathrm{HCl}$ and reacted with 3,3-diaminobenzidine tetrahydrochloride (DAB; Sig$\mathrm{ma} ; 0.5 \mathrm{mg} / \mathrm{ml}$ in Tris- $\mathrm{HCl}$ ) and $0.01 \%$ hydrogen peroxide. Sections were mounted on chrome-alum gelatin coated slides, dehydrated and coverslipped. Adjacent sections were Nissl stained.

Double staining was performed as described previously (Papa et al., 2003). Sections were incubated with anti-CGRP and anti-GFAP followed by incubation with a cocktail solution containing Alexa Fluor 488 antimouse IgG (1:200; Invitrogen, Carlsbad, CA) and Alexa Fluor 546 anti- 

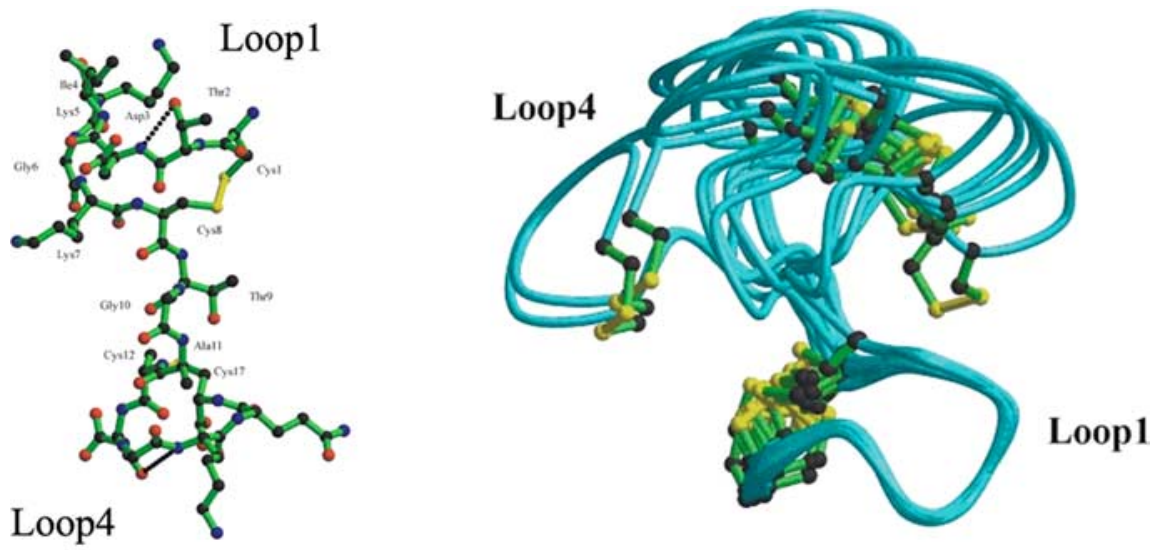

A

Figure 5. Structure of L1L4 peptide. $\boldsymbol{A}$, The lowest energy NMR model of L1L4. $\boldsymbol{B}, C^{\alpha}$ trace of the ensemble of the 20 NMR conformers of L1L4. The L1 moiety of the individual structures has been superimposed. The two disulfide bridges are also shown.

TrkA receptor. In particular, we took into account information based on mutagenesis analyses, structural investigations and previous characterizations of NGF-like peptides. On this basis, we selected three regions of the human NGF sequence: the N-terminal fragment, loop 1 (L1), and loop 4 (L4). As a starting point, the peptide NL1L4 incorporating the three regions was designed by using residues His4Asp24 of the N-terminal region, and residues Thr29-Lys34 and Asp92-Gln95 of the L1 and L4 regions, respectively. To restrain the conformational flexibility of L1 and L4, the two loops were cyclized by introducing four Cys residues at their extremities (Table 1). To reduce the number of possible disulfide bridges during the synthesis phase, Cys15 was mutated to Ala. A linker with sequence TGA was used to connect the two cyclic loops of NL1L4.

rabbit IgG (1:200; Invitrogen) for $2 \mathrm{~h}$. Sections were mounted and coverslipped with Vectashield (Vector Laboratories).

Confocal microscopy. To visualize three-dimensional (3D) relationship between $\mathrm{C}$-fibers and reactive astrocytes, slides were analyzed with a laser scanning microscope Zeiss (Oberkochen, Germany) LSM 510 Meta. Confocal images were acquired from the dorsal horn of the lumbar spinal cord. Images were captured at a resolution of $512 \times 512$ pixels. The appropriate argon laser fluorescence for visualization of the GFAP was used with an excitation wavelength of $488 \mathrm{~nm}$ and emission filter bandpass 505-530. The HeNe laser fluorescence for the CGRP signal with an excitation wavelength of $546 \mathrm{~nm}$ and emission filter long-pass 560 was used. To better analyze the close relationship between C-fibers and astrocytes, a series $(n=35)$ of single sections were acquired at $0.58 \mu \mathrm{m}$ apart and a 3D reconstruction was performed.

Measurements and statistical analysis. Slides were imaged with a Zeiss Axioskope 2 light microscope equipped with high-resolution digital camera; (C4742-95; Hamamatsu Photonics, Milan, Italy). Analysis of the markers in the dorsal horn of spinal cord was accomplished by using computer assisted image analysis system (MCID 7.0; Imaging Research, St. Catharines, Ontario, Canada). The densitometric values of the neuronal markers expressed the total target measured area relative to the scanned area. For glial markers only a morphometric approach was preferred because of the perfect visualization of single positive elements. Therefore, the values of the GFAP and ED1, markers for astrocytes and microglia respectively, were expressed as a proportional area: number of positive elements relative to the scanned area.

The averages were obtained from five randomly selected spinal cord sections for each animal and comparisons were made between treatment (L1L4 peptide, NGF, and ACSF) and CTR groups (sham operation). All data collection was performed in a blind manner: the observer making the measurements was not aware of the treatment to which each group was subjected. Data were exported and converted to frequency distribution histograms by using the SigmaPlot 10.0 program (SPSS, Erkrath, Germany).

Data from all the quantitative analyses were analyzed by one-way ANOVA, using all pairwise Holm-Sidak method for multiple comparisons. All data shown are presented as the mean \pm SEM.

Individual images of control and treated rats were assembled and then the same adjustments were made for brightness, contrast and sharpness using Adobe (San Jose, CA) Photoshop.

\section{Results}

\section{Design and synthesis of NGF mimetic peptides:} computational studies

The strategy used to design NGF agonists was based on the combination of different NGF regions known to interact with the
Molecular graphic sessions indicated that the length of the linker should allow the relative orientation of the two loops as found in the NGF structure.

To dissect the contribution of different regions to the NGF activity of the peptide, other peptides were designed. In particular, we analyzed the role of (1) N-terminal region (NL1L4 vs L1L4), (2) N-terminal charge (AcNL1L4 vs NL1L4, AcL1L4 vs L1L4), (3) individual cycles (L1L4 vs SSL1L4 and L1SSL4 containing single-loop cyclizations), (4) differences in human and mouse loop 4 sequence [L1L4 vs L1L4(E)]. Peptides containing a single cyclic loop (AcL1 and AcL4) were also investigated, as well as the cyclic homodimers L1L1 and L4L4. A list of the peptide sequences corresponding to the various constructions is reported in Table 1 . The purity of the various peptides used for biological assays was $>95 \%$.

\section{Bicyclic NGF-mimetic peptides induce differentiation of DRGs and PC12 cells}

The biological activity of NL1L4 was tested on DRGs, the original system where the neurotrophic activity of NGF was first observed (Levi-Montalcini, 1952). DRGs were cultured in complete medium containing NL1L4 $(3,6$ and $10 \mu \mathrm{M})$ or $2.5 \mathrm{~S} \mathrm{mNGF}(5 \mathrm{ng} / \mathrm{ml}$ corresponding to $0.192 \mathrm{~nm})$. As shown in Figure 1, $C$ and $D$, the peptide NL1L4 was able to induce DRG differentiation at concentrations as low as $3 \mu \mathrm{M}$ after $24-48 \mathrm{~h}$, to an extent substantially comparable with that induced by native $2.5 \mathrm{~S}$ mNGF $(0.192$ nM) (Fig. $1 B$ ), whereas control ganglia only showed fibroblast proliferation caused by the presence of serum in the culture medium (Fig. 1 $A$ ). The requirement for cyclization was also evaluated by analyzing the activity of peptide NL1L4 in the linear form. As shown in Figure $1 E$, linear NL1L4 did not induce DRG differentiation even at the highest concentration tested $(10 \mu \mathrm{M})$.

However, although the neurotrophic activity displayed by NL1L4 on DRGs was comparable with that induced by the native protein, the synthesis of this 38 aa peptide and its correct cyclization required a long and complex process. This prompted us to develop additional mimetic analogues characterized by relatively simpler structures. Among other molecules, the peptide L1L4 was found to induce DRG differentiation at the concentration of $3 \mu \mathrm{M}$ (Fig. $1 F$ ), suggesting that the $\mathrm{N}$-terminal chain was not critical for receptor dimerization and biological activity. In addition, L1L4 at concentrations of 3 and $6 \mu \mathrm{M}$ was also able to induce the differ- 
A

Von Frey Filament test

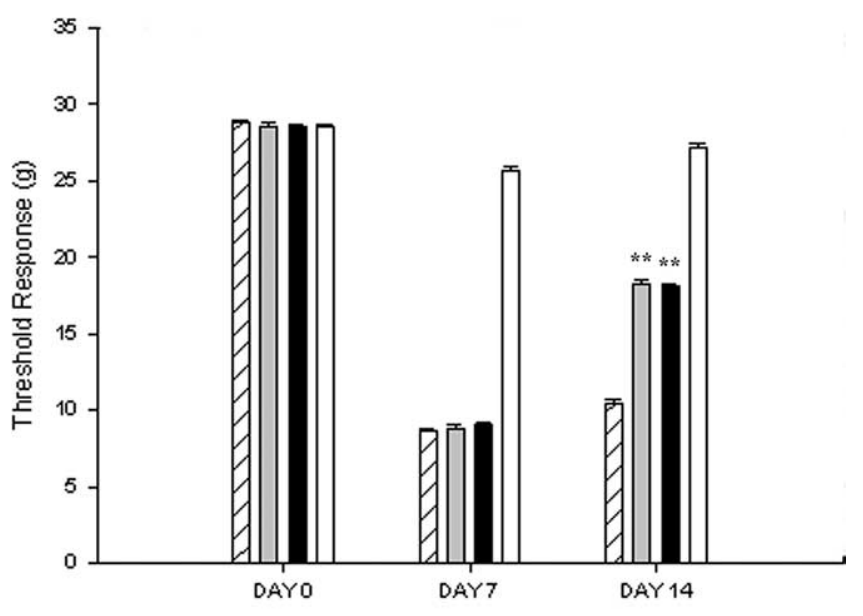

B

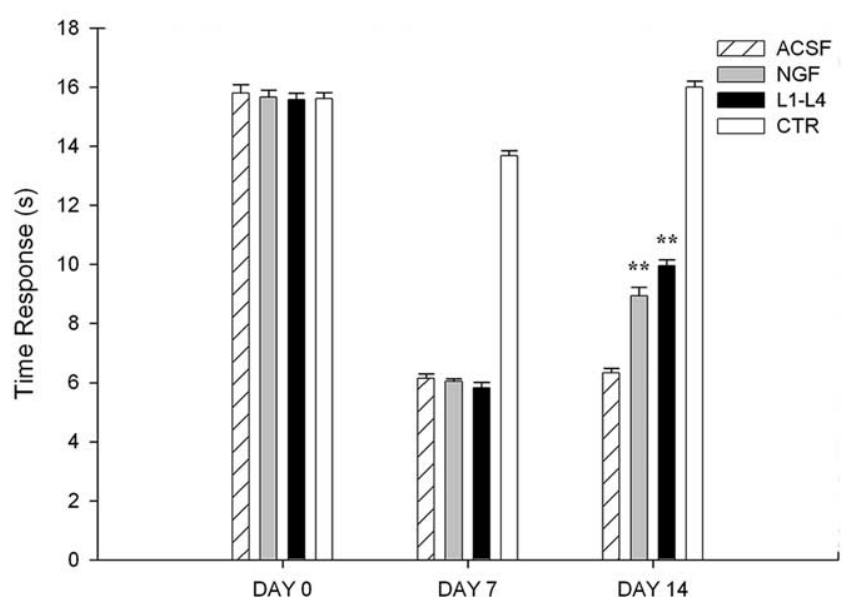

Figure 6. Recovery from CCl-induced neuropathic behavior by intrathecal administration of NGF or peptide $L 1 L 4 . A, B, C(\mathrm{C}$ - and sham-operated rats (total number of animals $n=30$ and 6 , respectively) were tested for responses to the von Frey test $(\boldsymbol{A})$ and the Plantar test $(\boldsymbol{B})$ for baseline sensitivity (day 0 ) and $7 \mathrm{~d}$ after the surgery (day 7 ). Rats were reassessed on day 14 after a $7 \mathrm{~d}$ intrathecal infusion of $\beta$-NGF (125 ng/ $\mu \mathrm{l} / \mathrm{hr}$ ) or peptide L1L4 $(37.5 \mu \mathrm{g} / \mu \mathrm{l} / \mathrm{hr}$ ) dissolved in ACSF (used as vehicle) or ACSF only. Data are the mean \pm SEM of two separate experiments with five independent samples ( $n=10$ for treated groups; $n=6$ for CTR group; ${ }^{* *} p<0.001$, NGF and L1L4 versus ACSF (ANOVA and Holm-Sidak test).

entiation of PC12(615) cells to an extent of $71 \pm 12.5$ and $75.9 \pm$ $17.4 \%$, respectively, of that induced by mNGF $(0.192 \mathrm{~nm})$ (Fig. $2 B)$. Representative images of the activity of L1L4 (3 and $6 \mu \mathrm{M}$ ) on PC12 cells differentiation are shown in Figure $2 \mathrm{~A}$, whereas the dose-response studies reported in Figure $2 \mathrm{C}$ indicate an $\mathrm{EC}_{50}$ of $\sim 1 \mu \mathrm{M}$. Similar activity was displayed by the peptide L1L4(E) (Figs. 2B,C) and the acetylated forms of these peptides (AcNL1L4 and AcL1L4) (data not shown).

\section{Induction of TrkA, but not TrkB, phosphorylation}

Activation of TrkA is the first event in the signaling cascade leading to differentiation and survival of NGF responsive neurons and PC12 cell (Greene and Tischler, 1976; Chao, 2003; Huang and Reichardt, 2003). To evaluate whether the neurotrophic activity of NGF-like peptides was mediated by the interaction with TrkA receptor, we analyzed their capability to induce TrkA phosphorylation in PC12(615) cells. The activity of peptides was tested in the range of concentrations that were effective on ganglia and PC12 cells differentiation. Data in Figure $3 A$ show that the peptide L1L4 at 3 and $6 \mu \mathrm{M}$ induced significant TrkA phosphorylation, $80 \pm 7.5$ and $75 \pm 9.5 \%$, respectively, of that obtained in cells treated with mNGF $(0.192 \mathrm{nM})$, whereas doseresponse studies with L1L4 confirmed an $\mathrm{EC}_{50}$ of $\sim 1.5 \mu \mathrm{M}$ (Fig. $3 B)$. A similar trend was observed for the L1L4(E) peptide which showed $76.2 \pm 15$ and $83.7 \%$ of mNGF activity, respectively at 3 and $6 \mu \mathrm{M}$ (Fig. 3A). Data in Figure 3, $A$ and $B$, also demonstrate the requirement of cyclization for proper receptor phosphorylation. In fact, although $\sim 20 \%$ lower than L1L4 and L1L4(E), the cyclic NL1L4 afforded a discrete level of TrkA phosphorylation, $56.8 \pm 9.5$ and $63.5 \pm 12 \%$ of $\mathrm{mNGF}$, at 3 and $6 \mu \mathrm{M}$, respectively. Instead, the linear peptide NL1L4 failed to induce a significant level of TrkA phosphorylation in PC12 cells even at the higher concentration of $10 \mu \mathrm{M}$ (Fig. $3 B$ ), in agreement with the lack of responsiveness that was observed also on DRGs.

Interaction of peptides with the TrkA receptor was also assessed in the presence of the tyrosine kinase inhibitor K252a. As shown in Figure 4, TrkA activation was completely abolished when cells were exposed to $\mathrm{K} 252 \mathrm{a}(100 \mathrm{nM})$ for $10 \mathrm{~min}$ before addition of NL1L4 (Fig. 4A), L1L4 (Fig. 4B), or mNGF. Moreover, Figure $4, A$ and $B$, also show a decrease of the p-TrkA band after 30 min incubations, in agreement with the kinetics of trkA activation by NGF (Jullien et al., 2002).

Given that DRGs also contain neurons responsive to BDNF (Davies et al., 1986), it was ascertained whether the activity shown by these bicyclic peptides could be in part caused by interaction with the TrkB receptor, although $\mathrm{L} 1$ and $\mathrm{L} 4$ belong to the variable NGF regions responsible for receptor specificity. To this purpose, we tested the specificity of the bicyclic peptide L1L4 on cerebellar granule cells that express TrkB, but not TrkA, receptors (Marini et al., 1998). TrkB phosphorylation was analyzed in granule neurons treated for $10 \mathrm{~min}$ with $\mathrm{rhBDNF}$ ( 10 and $20 \mathrm{ng} / \mathrm{ml}$ ), mNGF (10 and $100 \mathrm{ng} / \mathrm{ml})$, or L1L4 $(3,6$, and $10 \mu \mathrm{M})$. Figure $4 C$ shows that a band corresponding to $\mathrm{p}$-TrkB was present only in lysates from granule neurons treated with rhBDNF, but not in cells treated with mNGF or L1L4, even at the higher concentration of $10 \mu \mathrm{M}$, thus confirming that the activity displayed by this peptide on DRGs was only caused by its interaction with the TrkA receptor.

\section{Both L1 and L4 loops are required for proper biological activity}

Cyclic and homodimeric cyclic peptides have been shown to function as a partial NGF agonist (Longo et al., 1997; Xie et al., 2000). Our data indicate that L1L4 exerts biological activity at concentrations much lower than those reported in the literature, suggesting that the presence of two distinct loops is another important structural requirement for proper receptor activation. This hypothesis was tested by comparing the activity L1L4 with that of single-loop analogues (AcL1 and AcL4) or L1L4 with single-loop cyclizations (SSL1L4 and L1SSL4). None of these single-loop structural analogues was able to induce the differentiation of DRGs (data not shown). These results were confirmed by the lack of response on PC12 cells differentiation (Fig. 2 B, C), that was correlated to the low levels of TrkA phosphorylation induced by AcL1 and AcL4 (Fig. $3 A$ ) and SSL1L4 and L1SSL4 (data not shown). Moreover, their activity was not increased by culturing ganglia or PC12(615) with a mixture of the single-loop structural analogues (AcL1 plus AcL4, SSL1L4 plus L1SSL4), at both 3 and $6 \mu \mathrm{M}$ each (data not shown).

Partial agonist activity was instead achieved with the ho- 


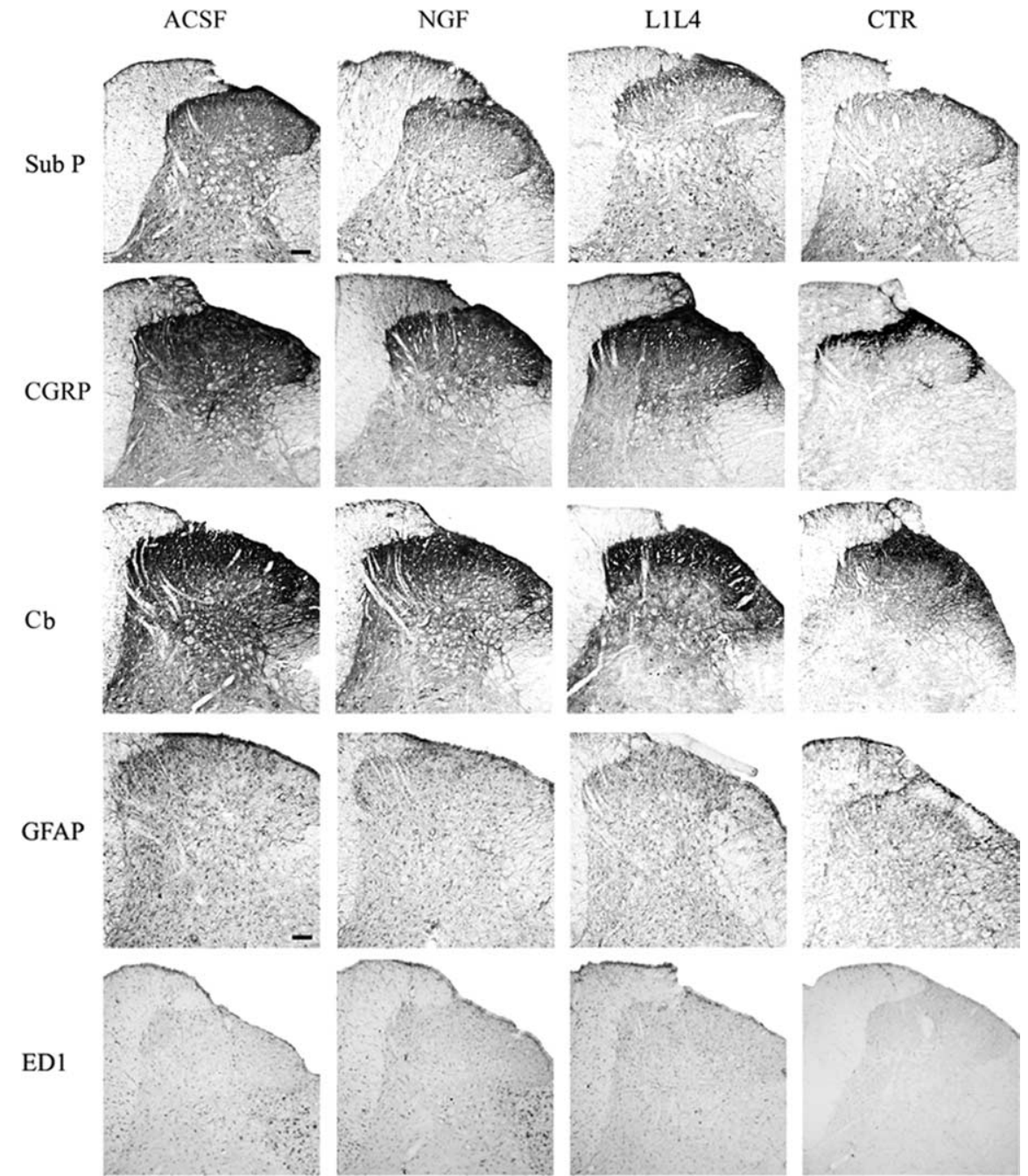

Figure 7. Immunocytochemistry of dorsal horn of the lumbar spinal cord. Sham- (CTR) and CCl-operated animals treated for $7 \mathrm{~d}$ by intrathecal infusion of NGF (125 ng/ $\mu \mathrm{l} / \mathrm{hr})$ or peptide L1L4 $(37.5 \mu \mathrm{g} / \mu \mathrm{l} / \mathrm{hr})$ were killed on day 14 as described in Materials and Methods. Sections of dorsal horn of the lumbar spinal cord were immunostained for Sub P, CGRP, Cb, GFAP, and ED1 by incubation with the primary antibody followed by the appropriate biotinylated secondary antibody. Samples were then processed by the Vectastain avidin-biotin peroxidase kit (Vector Laboratories) and reaction with DAB and $0.01 \%$ hydrogen peroxide. Sections were mounted on chrome-alume gelatin coated slides and imaged with a Zeiss Axioskope 2 light microscope equipped with high-resolution digital camera (C4742-95; Hamamatsu Photonics). Scale bar, $50 \mu \mathrm{m}$. Adjacent sections were Nissl-stained.

bone superposition of the best 20 CYANA conformers are reported in Figure $5 A$. The abundance of $\alpha \mathrm{N}$ sequential connectivities suggests that the majority of L1L4 conformers exhibits in solution extended conformation of the backbone. Although $\alpha \mathrm{H}$ proton chemical shift deviations of the amino acid residues from their corresponding random coil values suggest the absence of ordered secondary structures, the individual rings of L1L4 are rather rigid. The root mean square deviation (RMSD) of L1 and L4, calculated on backbone atoms, among the structure of the ensemble is 0.22 and $0.20 \AA$, respectively. A relevant degree of flexibility is exhibited by side chains. Indeed, RMSD of L1 and L4, calculated on both side and main atoms, increases up to 0.83 and $0.71 \AA$. The lack of strong long-range NOE indicates that their relative position could not be uniquely defined. The overall structure of the peptide can be described as two rather rigid loops connected by a rather flexible linker (Fig. 5B).

\section{Effect of L1L4 peptide on neuropathic pain}

Given that NGF is a trophic factor for small fiber sensory and sympathetic neurons, we tested the NGF-like activity of the peptide L1L4 on an animal model of peripheral neuropathy. Animals were tested for neuropathic pain behavior on days 0,7 , and 14 after CCI (Bennet and Xie, 1998) by analyzing mechanical and thermal sensitivity.

The mean baseline of normal mechanical resistance recorded before the damage (day 0 ) was $28.61 \pm 0.12$ across the different experimental groups. In shamoperated (CTR) animals, this value was unmodified and mechanical sensitivity values recorded were $25.63 \pm 0.32$ and

modimeric peptides L1L1 and L4L4, although at concentrations lower than those reported previously (Longo et al., 1997; Xie et al., 2000). As shown in Figure $3 A$, these peptides at the concentrations of 3 and $6 \mu \mathrm{M}$ induced $\sim 50 \%$ of the phosphorylation given by mNGF $(50.2 \pm 3.5$ and $53.5 \pm 4 \%$ for L1L1, respectively; $51.65 \pm 6.7$ and $49.1 \pm 4.5 \%$ for L4L4), and this activity was correlated to the lower levels of PC12 cells differentiation at 3 and $6 \mu \mathrm{M}(28.3 \pm 9$ and $38.5 \pm 5.6$ for L1L1; $34.7 \pm 8.5$ and $38 \pm 2.5$ for L4L4) (Fig. 2B, C).

\section{Conformational properties of bicyclic peptide L1L4}

To acquire insight into the mechanism of action of the peptide L1L4, its structure was determined by NMR. A virtually complete proton assignment of the L1L4 peptide was accomplished by a careful inspection of TOCSY, NOESY, and DQF-COSY spectra following standard procedures. These structural constraints were used to generate a total of 100 structures and among them the 20 structures with the lowest target function values were selected and energy minimized. The lowest energy structure and back-
$27.22 \pm 0.18$ on day 7 and day 14 after sham operation, respectively (Fig. 6A). CCI-operated rats, instead, showed a significant reduction in mechanical nociceptive threshold on day 7 after surgery and presented an earlier mechanical response of $8.8 \pm 0.2$ indicative of an allodynic state. In the CCI-rats, intrathecal infusion of either rat recombinant $\beta$-NGF $(125 \mathrm{ng} / \mu \mathrm{l} / \mathrm{hr}$ ) or L1L4 peptide $(37.5 \mu \mathrm{g} / \mu \mathrm{l} / \mathrm{hr})$ for $7 \mathrm{~d}$ restored the mechanical sensitivity to $18.30 \pm 0.2$ and $18.09 \pm 0.2$, respectively, compared with the animals treated with ACSF used as vehicle $(10.46 \pm 0.27)$ $(p<0.001)$ (Fig. 6A).

The Hargreaves behavioral test (Hargreaves et al., 1988) in CCI-treated animals also showed a strong reduction of the reaction time to the thermal stimulus on day 7 after CCI surgery with a very short time-response to infrared stimulation (6.00 \pm $0.25 \mathrm{~s}$ ), compared with basal values of $15.66 \pm 0.29 \mathrm{~s}$ of normal thermal sensitivity (Fig. $6 \mathrm{~B}$ ), indicating the onset of a hyperalgesic state. Hargreaves test recordings in the CTR group were almost unmodified on day $7(13.67 \pm 0.16)$ and day $14(16 \pm 0.2)$ after sham surgery. The hyperalgesic behavior was still evident in 

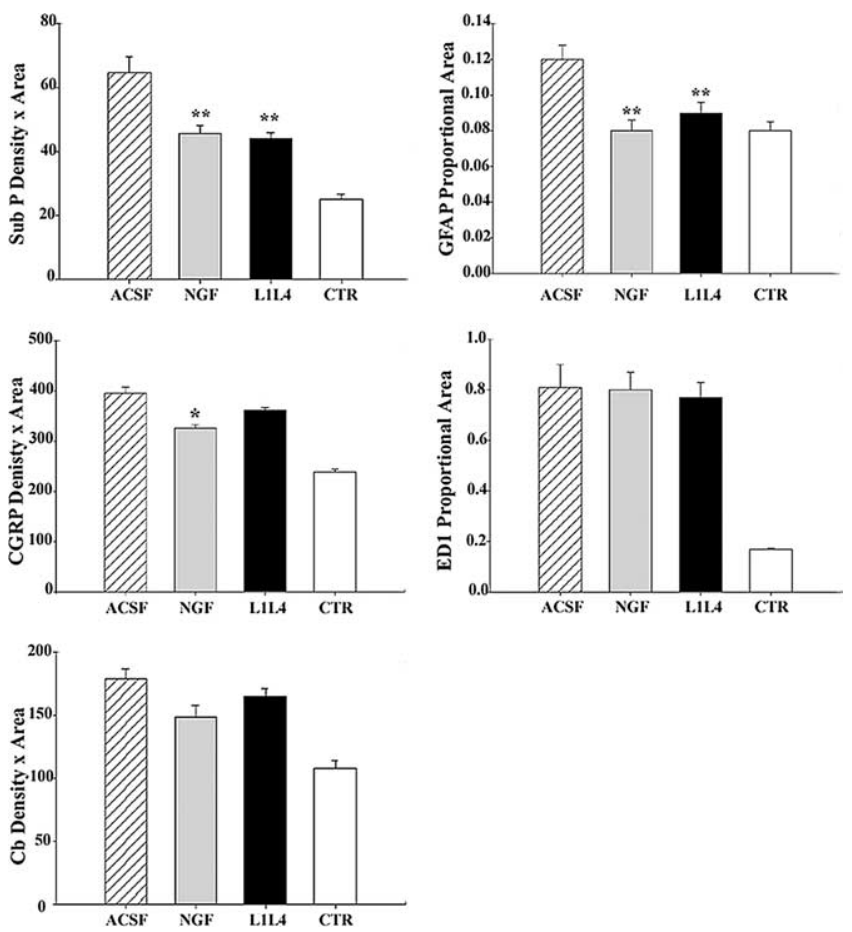

Figure 8. Markers quantitation in the dorsal horn of lumbar spinal cord. Densitometric analysis of markers in the dorsal horn of spinal cord was accomplished by using computer assisted image analysis system (MCID 7.0) and expressed as total target measured area relative to the scanned area. In the left column, the densitometric values of neuronal fiber markers (Sub P, (GRP, (b) are expressed as density $X$ area. In the right column, the morphometric values of astrocytic (GFAP) and microglial (ED1) labeling are expressed as proportional area ( $n=10$ for treated group; $n=6$ for (TR group). ${ }^{* *} p<0.001$ and ${ }^{*} p<0.01$, NGF and L1L4 versus ACSF (ANOVA and Holm-Sidak test).

all the ACSF-treated animals and no improvement was found on day 14 after $7 \mathrm{~d}$ of vehicle infusion (6.34 \pm 0.13$)$. Among the CCI-operated rats, instead, we found that administration of $\beta$-NGF or L1L4 peptide significantly restored thermal sensitivity to $8.93 \pm 0.29$ and $9.96 \pm 0.19$, respectively, $(p<0.001)$ (Fig. 6B).

\section{Immunocytochemical assessment of the fiber sprouting after CCI in the rat spinal cord}

The effect of NGF and L1L4 peptide administration to CCIanimals was evident also at a biochemical/structural level (Figs. 7, 8), as determined by immunohistochemical analysis of Sub P and CGRP, two neuropeptides markers of primary afferent fibers of the spinal cord (Ji and Strichartz, 2004). In the CCI-ACSF group we found an intense staining for Sub P $(64.89 \pm 4.86)$ compared with CTR group $(24.93 \pm 0.11)$, and its expression levels were partially restored in $\beta$-NGF- $(45.83 \pm 2.36)$ and L1L4- $(44.03 \pm$ $2.04)$ treated animals $(p<0.001)$ (Figs. 7,8). A similar trend was shown for CGRP staining. We found that $14 \mathrm{~d}$ after CCI the expression of CGRP in the dorsal horn of the ACSF-treated rats was intense $(395.84 \pm 12.48)$ compared with the CTR group (238.79 \pm 6.42$)$, whereas densitometric evaluation of CGRP staining in the spinal cord of $\beta$-NGF and L1L4 groups indicated a reduction to $326.51 \pm 6.84(p<0.01)$ and $362.3 \pm 5.16$, respectively (Figs. 7, 8).

Less relevant appeared the effect of NGF and L1L4 treatments on the damage to A- $\delta$ fibers entering the spinal cord, as assessed by $\mathrm{Cb}$ staining (Ji and Strichartz, 2004). The densitometric value for Cb staining in the CCI-ACSF group was $179.31 \pm 7.45$, higher than in CTR group $(107.8 \pm 6.41)$, and it was only partially reduced in $\beta$-NGF-treated rats $(149.01 \pm 8.67)$ and to some extent in L1L4-treated animals $(164.97 \pm 6.53)$ (Figs. 7, 8).

Immunocytochemical assessment of glial cells response after $\mathrm{CCI}$ in the rat spinal cord

The effects evoked by the $7 \mathrm{~d}$ infusion of NGF and L1L4 peptide on neuropathic behavior on day 14 after CCI prompted us to evaluate their potential activity on gliosis, a common response to the nervous system injury. Our results revealed the presence of marked gliosis in the dorsal horn of the spinal cord in the CCIACSF group, as expressed by the intense staining for GFAP $(0.12 \pm 0,008)$ compared with CTR group $(0.08 \pm 0.005)$ (Figs. 7 , $8)$. Treatments with $\beta$-NGF or L1L4 peptide restored GFAP levels to $0.08 \pm 0.006$ and $0.09 \pm 0.006$, respectively $(p<0.001)$ (Figs. $7,8)$. The massive gliosis found in the dorsal horn of the spinal cord of ACSF-treated animals represents a peculiar transformation of astrocytes from protoplasmic to fibrillary type. This means that the intense staining is caused by hypertrophy of single cells rather than a marked increase in the total number of glial cells.

No changes were found at the level of reactive microglia, as determined by the staining for ED1, the marker for reactive microglia (Ji and Strichartz, 2004). In fact, we found that $14 \mathrm{~d}$ after CCI, ED1 expression was significantly higher in the dorsal horn of the ACSF group $(0.81 \pm 0.09)$, compared with CTR $(0.17 \pm$ $0.004)$, and was not changed by the $7 \mathrm{~d}$ infusion of $\beta$-NGF $(0.8 \pm$ $0.07)$ or L1L4 peptide $(0.77 \pm 0.06)$ (Figs. 7,8$)$. These results clearly indicate that the administration of NGF or L1L4 peptide does not interfere with microglial reaction and that this process is not functionally related to the hyperalgesia and/or allodynic behavior.

Confocal microscopy allowed us to visualize a rearrangement of the neuroglial network (Fig. 9). CGRP labeling showed an intense sprouting of $\mathrm{C}$-fibers in close relation with fibrillary astrocytes (Fig. 9A). The insurgence of gliosis seemed to positively correlate with the sprouting of nociceptive fibers and was partially reversed by treatment with $\beta$-NGF or L1L4 peptide (Fig. $9 A)$. The $3 \mathrm{D}$ reconstruction and the free rotation allowed us to visualize the fibrillary glia that disaggregated most of the C-fibers and often single fibers appeared to be fully ensheathed by astrocytes protrusion (Fig. 9B, C).

\section{Discussion}

Together, the results reported in this paper offer a strong, novel contribution of great interest for potential therapeutic applications of NGF and derived molecules. A NGF-mimetic peptide (L1L4) was shown to be active in vitro at the concentration of 3 $\mu \mathrm{M}$ (and with an $\mathrm{EC}_{50}$ of $1 \mu \mathrm{M}$ ) well below the range of concentrations reported for the more active homopeptides (Longo et al., 1997; Xie et al., 2000) and, more relevantly, the same L1L4 peptide was effective in reducing neuropathic pain in animal CCI models to an extent comparable with that given by the NGF protein.

The choice to link in the same molecule both L1 and L4 loops was critical for the construction of the active peptide. L1L4 induced the differentiation of DRGs and the molecular mechanisms activated by this peptide required the phosphorylation of TrkA, but not TrkB, receptor (Fig. 4). The determination of the solution NMR structure of the L1L4 peptide indicates that it adopts an extended conformation characterized by two rather rigid loops connected by a flexible linker. This structure is compatible with a functional mechanism based on the ability of L1L4 
A

ACSF
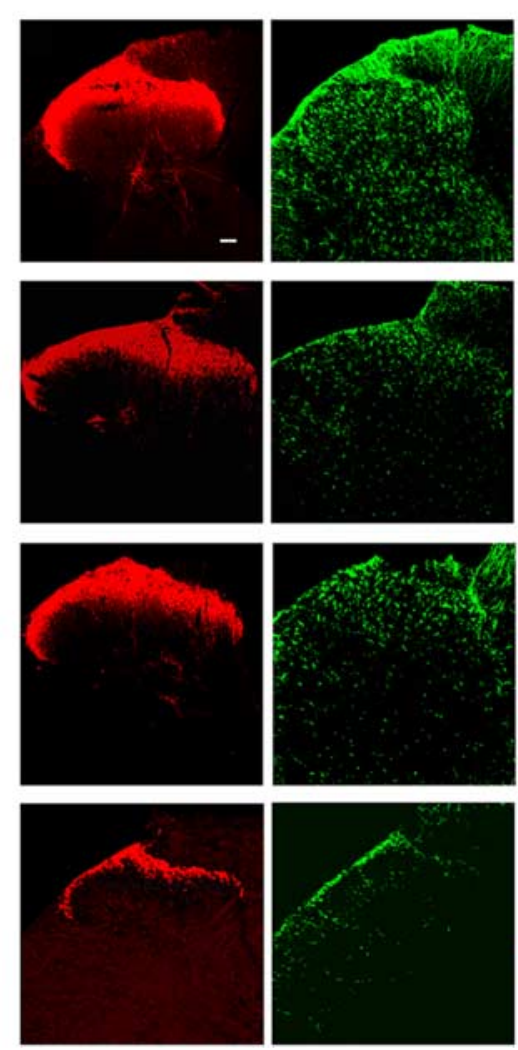

MERGE
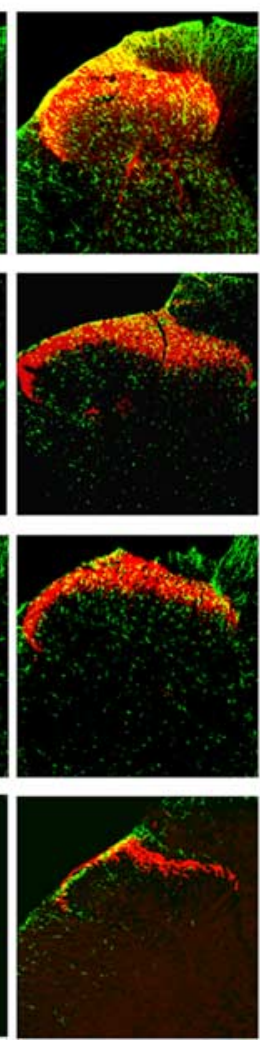

B
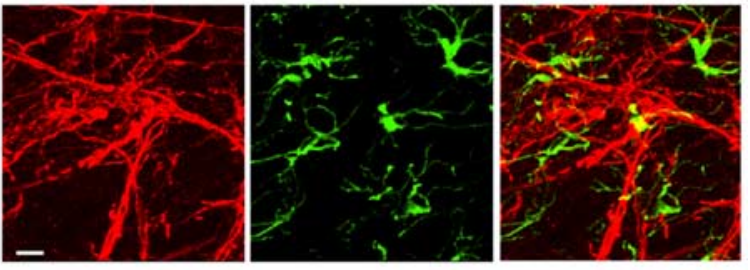

c

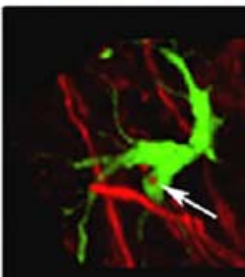

Figure 9. Confocal microscopy images of dorsal horn of the lumbar spinal cord $14 \mathrm{~d}$ after CCl show changes of the neuroglial network. $\boldsymbol{A}$, In the ACSF group high density of C-fibers is evident into the laminas I and II as shown by CGRP labeling. In the same laminas GFAP fibrillary reactive astrocytes appear hypertrophic, and a close relationship between gliosis and C-fibers sprouting is clearly evident (merged images). This condition was partially reversed by treatment with $\beta$-NGF or L1L4 peptide. Scale bar, $50 \mu \mathrm{m}$. B, Confocal microscopy images of dorsal horn of the lumbar spinal cord $14 \mathrm{~d}$ after CCl show modified relationship between C-fibers (CGRP positive) and reactive astrocytes (GFAP staining) forming the neuroglial network (merge). Scale bar, $10 \mu \mathrm{m}$. $C$, $3 \mathrm{D}$ reconstruction and free rotation allowed to characterize the behavior of the hypertrophic astrocytes (green) showing that the fibrillary glia disaggregate most of the C-fibers (red) and often one single fiber appeared to be fully ensheathed by astrocyte protrusion (arrow).

to induce TrkA dimerization, the flexible linker being relevant for the correct anchoring of interacting TrkA domains. The presence of a covalent linker between the two moieties was shown to be a necessary requirement for NGF-like activity because mixtures of the two cyclic single loops (AcL1 and AcL4) did not have significant biological action. In addition, our data also clearly confirmed previous findings regarding the requirement of cyclization, as the cyclic, but not the linear, form of NL1L4 was able to induce DRG differentiation and TrkA phosphorylation in PC12(615) cells.

To fill up the gap between cyclic monomeric and bicyclic peptides, we also compared the activity of L1L4 to the homodimeric molecules L1L1 and L4L4. In agreement with previous published data (Longo et al., 1997; Xie et al., 2000), these peptides behaved as partial agonist by inducing TrkA phosphorylation and differentiation of PC12(615) cells, $50 \%$ of that observed with mNGF. However, it should be noted that our homodimeric peptides, L1L1 and L4L4, showed agonist activities at concentration of $3 \mu \mathrm{M}$, which is significantly lower than those previously reported. These differences may be ascribed to the higher flexibility of our molecules. The overall data indicate that the presence of both loops in the same molecule [NL1L4, L1L4 and L1L4(E)] was a major requirement to obtain NGF-like peptides with activity comparable with the native protein, as shown by the TrkA phosphorylation and the correlated differentiation levels in PC12 cells (Figs. 2, 3).

An interesting aspect of this study is that both NGF and the peptide L1L4 were found to be effective in the CCI model of neuropathic pain, a severe and persistent pathological condition very often refractory to therapy. Our data indicate that i.t. administration of L1L4 to injured rats was able to reduce thermal and mechanical sensitivity to an extent comparable with that obtained with $\beta$-NGF (Fig. 6). The results of behavioral tests were confirmed by biochemical/structural assays, as indicated by the effects of 7-day treatments on Sub P and, to some extent, on CGRP staining. Another example of NGF molecules active on the CNS is given by the peptidomimetic D3, a partial agonist ligand of TrkA, that was found to be effective in the in vivo model of cognitive impairment of aging (Bruno et al., 2004).

In the CCI model of neuropathic pain, fibers in the nerve are spared and remain intact, although they run through an abnormal environment. Our data show that NGF is required for maintaining the neurochemical homeostasis of nociceptive neurons in the spinal cord after traumatic injury, and comparable effects were obtained with L1L4 administration. Data shown in Figures 7 and 8 clearly indicate that both NGF and L1L4 treatments strongly reduced the expression of Sub $\mathrm{P}$ and, to some extent also CGRP, the two neuronal markers of nociceptive neurons. In contrast, the activity of NGF protein and the derived molecule L1L4 was found less relevant on $\mathrm{A} \delta$ fibers, as indicated by the $\mathrm{Cb}$ staining (Figs. 7, 8).

Our behavioral data are apparently in contrast with other studies on nociception and neuropathic pain. In fact, systemic and local administration of NGF have been shown to induce algesia (Ro et al., 1999), suggesting that anti-NGF antibodies 
might be used as a therapy for neuropathic pain (Ro et al., 1999; Wild et al., 2007). Indeed, algesia is a known side effect of systemic and local applications of NGF even in clinical trials (Apfel, 2002). However, on the other hand it is also well known that NGF is the neurotrophic factor for small peripheral sensory neurons (Levi-Montalcini, 1952; Gold et al., 1991) and when centrally administered has an anti-nociceptive activity (Ren et al., 1995; Cahill et al., 2003; Sah et al., 2003). These studies suggest that NGF supplementation may be beneficial in restoring and/or maintaining opioid analgesia in chronic pain conditions (Cahill et al., 2003), in agreement with the indicated role of NGF as a modulator of $\mu$ opiate receptors (McMahon et al., 2006; Pezet and McMahon, 2006).

In addition, we here report a novel and crucial role of i.t. administered NGF as a modulator of neuronal-glial network plasticity by reducing reactive gliosis to peripheral nerve damage, an effect that is well correlated with the role of glial cells in the development of morphine tolerance in vivo (Song and Zhao, 2001). As extensively revised by Scholz and Woolf (2007), longterm glial changes are relevant to the establishment of morphological and molecular features underlying neuropathic pain. Moreover, the interaction between glial and neuronal cells seems to be necessary, or strongly contribute, to several neurodegenerative processes (Lobsiger and Cleveland, 2007). Neuropathic pain management is currently aimed only at reducing symptoms, generally by suppressing neuronal activity. In contrast, modulating the immune response to nerve injury and targeting glia may provide a mean for disease modification by aborting neurobiological alterations that support the development of persistent pain. Thus, our data suggest a novel mechanism whereby NGF, and NGF-like peptides, might be considered as an effective and resolutive therapy for neuropathic pain and several brain disorders involving glial components. In addition, we provide further evidence that intrathecal administration does not cause the algesic effects of NGF reported after systemic therapies (Apfel, 2002), which has limited NGF development as a drug.

In conclusion, the results presented in this paper offer new interesting perspectives for NGF and NGF-derived molecules and their potential for the treatment of peripheral neuropathies, and more generally for glial cell changes associated to non-cellautonomous neurodegenerative disorders.

\section{References}

Aloe L, Calzà L (eds.) (2004) Progress in brain research, Vol 146, NGF and related molecules in health and diseases. Amsterdam: Elsevier.

Apfel SC (2002) Nerve growth factor for the treatment of diabetic neuropathy: what went wrong, what went right, and what does the future hold? Int Rev Neurobiol 50:393-413.

Bai YH, Takemitsu M, Atsuta Y, Matsuno T (1999) Peripheral mononeuropathy induced by loose ligation of the sciatic nerve in the rat: behavioral, electrophysiological and histopathologic studies. Exp Anim 48:87-94.

Bartels C, Xia T, Billeter M, Güntert P, Wüthrich K (1995) The program XEASY for computer-supported NMR spectral analysis of biological macromolecules. J Biomol NMR 5:1-10.

Bennet GJ, Xie YK (1998) A peripheral mononeuropathy in rat that produces disorders of pain sensation like those seen in man. Pain 33:87-107.

Bradshaw RA, Murray-Rust J, Ibànez CF, McDonald NQ, Lapatto R, Blundell TL (1994) Nerve growth factor: structure/function relationship. Protein Sci 3:1901-1913.

Bruno MA, Clarke PB, Seltzer A, Quirion R, Burgess K, Cuello AC, Saragovi HU (2004) Long-lasting rescue of age-associated deficits in cognition and the CNS cholinergic phenotype by a partial agonist peptidomimetic ligand of TrkA. J Neurosci 24:8009-8018.

Cahill CM, Dray A, Coderre TJ (2003) Intrathecal nerve growth factor re- stores opioid effectiveness in an animal model of neuropathic pain. Neuropharmacology 45:543-552.

Chao MV (2003) Neurotrophins and their receptors: a convergence point for many signalling pathways. Nat Rev Neurosci 4:299-309.

Chaplan SR, Bach FW, Pogrel JW, Chung JM, Yaksh TL (1994) Quantitative assessment of tactile allodynia in the rat paw. J Neurosci Methods 53:55-63.

Coderre TJ (1992) Contribution of protein kinase C to central sensitization and persistent pain following tissue injury. Neurosci Lett 140:181-184.

Colangelo AM, Finotti N, Ceriani M, Alberghina L, Martegani E, Aloe L, Lenzi L, Levi-Montalcini R (2005) Recombinant human nerve growth factor with a marked activity in vitro and in vivo. Proc Natl Acad Sci USA 102:18658-18663.

Davies AM, Thoenen H, Barde YA (1986) The response of chick sensory neurons to brain-derived neurotrophic factor. J Neurosci 6:1897-1904.

Drinkwater CC, Barker PA, Suter U, Shooter EM (1993) The carboxyl terminus of nerve growth factor is required for biological activity. J Biol Chem 268:23202-23207.

Gold BG, Mobley WC, Matheson SF (1991) Regulation of axonal caliber, neurofilament content, and nuclear localization in mature sensory neurons by nerve growth factor. J Neurosci 11:943-955.

Greene LA, Tischler AS (1976) Establishment of a noradrenergic clonal line of rat adrenal pheochromocytoma cells which respond to nerve growth factor. Proc Natl Acad Sci USA 73:2424-2428.

Griesinger C, Otting G, Wuthrich K, Ernst RR (1988) Clean tocsy for H-1 spin system-identification in macromolecules. J Am Chem Soc 110:7870-7872.

Guex N, Peitsch MC (1997) SWISS-MODEL and the Swiss-PdbViewer: an environment for comparative protein modeling. Electrophoresis 18:2714-2723.

Guntert P, Wider G, Wuthrich K (1992) Processing of multidimensional NMR data with the new software prosa. J Biomol NMR 2:619-629.

Hargreaves K, Dubner R, Brown F, Flores C, Joris J (1988) A new and sensitive method for measuring thermal nociception in cutaneous hyperalgesia. Pain 32:77-88.

Hempstead BL, Rabin SJ, Kaplan L, Reid S, Parada LF, Kaplan DR (1992) Overexpression of the trk tyrosine kinase rapidly accelerates nerve growth factor-induced differentiation. Neuron 9:883-896.

Herrmann T, Güntert P, Wüthrich K (2000) Protein NMR structure determination with automated NOE assignment using the new software CANDID and the torsion angle dynamics algorithm DYANA. J Mol Biol 319:209-227.

Huang EJ, Reichardt LF (2003) Trk receptors: roles in neuronal signal transduction. Annu Rev Biochem 72:609-642.

Ibànez CF, Ebendal T, Barbany G, Murray-Rust J, Blundell TL, Persson H (1992) Disruption of the low affinity receptor-binding site in NGF allows neuronal survival and differentiation by binding to the trk gene product. Cell 69:329-341.

Ji RR, Strichartz G (2004) Cell signaling and the genesis of neuropathic pain. Sci STKE 252:reE14.

Jullien J, Guili V, Reichardt LF, Rudkin BB (2002) Molecular kinetics of nerve growth factor receptor trafficking and activation. J Biol Chem 277:38700-38708.

Kahle P, Burton LE, Schmelzer CH, Hertel C (1992) The amino terminus of nerve growth factor is involved in the interaction with the receptor tyrosine kinase $\mathrm{p} 140^{\text {trkA }}$. J Biol Chem 267:22707-22710.

Krüttgen A, Heymach JV, Kahle PJ, Shooter EM (1997) The role of the nerve growth factor carboxyl terminus in receptor binding and conformational stability. J Biol Chem 272:29222-29228.

Kullander K, Kaplan D, Ebendal T (1997) Two restricted sites on the surface of the nerve growth factor molecule independently determine specific trkA receptor binding and activation. J Biol Chem 272:9300-9307.

Kumar A, Ernst RR, Wüthrich K (1980) A two-dimensional nuclear Overhauser enhancement (2D NOE) experiment for the elucidation of complete proton-proton cross-relaxation networks in biological macromolecules. Biochem Biophys Res Commun 95:1-6.

LeSauteur L, Wei L, Gibbs BF, Saragovi HU (1995) Small peptide mimics of nerve growth factor bind TrkA receptors and affect biological responses. J Biol Chem 270:6564-6569.

Levi-Montalcini R (1952) Effects of mouse tumor transplantation on the nervous system. Ann NY Acad Sci 55:330-343. 
Levi-Montalcini R (1987) The nerve growth factor 35 years later. Science 237:1154-1162.

Lobsiger CS, Cleveland DW (2007) Glial cells as intrinsic components of non-cell-autonomous neurodegenerative disease. Nat Neurosci 10:1355-1360.

Longo FM, Vu TK, Mobley WC (1990) The in vitro biological effect of nerve growth factor is inhibited by synthetic peptides. Cell Regul 1:189-195.

Longo FM, Manthorpe M, Xie YM, Varon S (1997) Synthetic NGF peptide derivatives prevent neuronal death via a p75 receptor-dependent mechanism. J Neurosci Res 48:1-17.

Maliartchouk S, Debeir T, Beglova N, Cuello AC, Gehring K, Saragovi HU (2000a) Genuine monovalent ligands of TrkA nerve growth factor receptors reveal a novel pharmacological mechanism of action. J Biol Chem 275:9946-9956.

Maliartchouk S, Feng Y, Ivanisevic L, Debeir T, Cuello AC, Burgess K, Saragovi HU (2000b) A designed peptidomimetic agonistic ligand of TrkA nerve growth factor receptors. Mol Pharmacol 57:385-391.

Marini AM, Rabin SJ, Lipsky RH, Mocchetti I (1998) Activity-dependent release of brain-derived neurotrophic factor underlies the neuroprotective effect of N-methyl-D-aspartate. J Biol Chem 273:29394-29399.

McDonald NQ, Chao MV (1995) Structural determinants of neurotrophin action. J Biol Chem 270:19669-19672.

McDonald NQ, Lapatto R, Murray-Rust J, Gunning J, Wlodawer A, Blundell TL (1991) New protein fold revealed by a 2.3 A resolution crystal structure of nerve growth factor. Nature 354:411-414.

McMahon SB, Bennet DL, Bevan S (2006) Inflammatory mediators and modulators. In: Text-book of pain (McMahon SB, Koltzenburg M, eds), pp 49-72. London: Elsevier.

Papa M, Boscia F, Canitano A, Castaldo P, Sellitti S, Annunziato L, Taglialatela M (2003) Expression pattern of the ether-a-gogo-related (ERG) K+ channel-encoding genes ERG1, ERG2, and ERG3 in the adult rat central nervous system. J Comp Neurol 466:119-135.

Peleshok J, Saragovi HU (2006) Functional mimetics of neurotrophins and their receptors. Biochem Soc Trans 34:612-617.

Pezet S, McMahon SB (2006) Neurotrophins: mediators and modulators of pain. Annu Rev Neurosci 29:507-538.

Poduslo JF, Curran GL (1996) Permeability at the blood-brain and bloodnerve barriers of the neurotrophic factors: NGF, CNTF, NT-3, BDNF. Mol Brain Res 36:280-286.

Rance M, Sorensen OW, Bodenhausen G, Wagner G, Ernst RR, Wüthrich K (1983) Improved spectral resolution in COSY 1H NMR spectra of pro- teins via double quantum filtering. Biochem Biophys Res Commun $117: 479-481$

Ren K, Thomas DA, Dubner R (1995) Nerve growth factor alleviates a painful peripheral neuropathy in rats. Brain Res 699:286-292.

Ro LS, Chen ST, Tang LM, Jacobs JM (1999) Effect of NGF and anti-NGF on neuropathic pain in rats following chronic constriction injury of the sciatic nerve. Pain 79:265-274.

Rydén M, Ibàñez CF (1997) A second determinant of binding to the p75 neurotrophin receptor revealed by Alanine-Scanning mutagenesis of a conserved loop in nerve growth factor. J Biol Chem 272:33085-33091.

Sah DW, Ossipo MH, Porreca F (2003) Neurotrophic factors as novel therapeutics for neuropathic pain. Nat Rev Drug Discov 2:460-472.

Scholz J, Woolf CJ (2007) The neuropathic pain triad: neurons, immune cells and glia. Nat Neurosci 10:1361-1368.

Shih A, Laramee GR, Schmelzer CH, Burton LE, Winslow JW (1994) Mutagenesis identifies amino-terminal residues of nerve growth factor necessary for Trk receptor binding and biological activity. J Biol Chem 269:27679-27686.

Song P, Zhao ZQ (2001) The involvement of glial cells in the development of morphine tolerance. Neurosci Res 39:281-286.

Urfer R, Tsoulfas P, O’Connell L, Hongo JA, Zhao W, Presta LG (1998) High resolution mapping of the binding site of trkA for nerve growth factor and trkC for Neurotrophin-3 on the second immunoglobulin-like domain of the trk receptors. J Biol Chem 273:5829-5840.

Wiesmann C, Ultsch MH, Bass SH, de Vos AM (1999) Crystal structure of nerve growth factor in complex with the ligand-binding domain of the TrkA receptor. Nature 401:184-188.

Wild KD, Bian D, Zhu D, Davis J, Bannon AW, Zhang TJ, Louis JC (2007) Antibodies to nerve growth factor reverse established tactile allodynia in rodent models of neuropathic pain without tolerance. J Pharmacol Exp Ther 322:282-287.

Williams BJ, Eriksdotte-Jonhagen M, Granholm AC (2006) Nerve growth factor in treatment and pathogenesis of Alzheimer's disease. Prog Neurobiol 80:114-128.

Woo SB, Timm DE, Neet KE (1995) Alteration of NH2-terminal residues of nerve growth factor affects activity and Trk binding without affecting stability or conformation. J Biol Chem 270:6278-6285.

Xie Y, Tisi MA, Yeo TT, Longo FM (2000) Nerve growth factor (NGF) loop 4 dimeric mimetics activate ERK and AKT and promote NGF-like neurotrophic effects. J Biol Chem 275:29868-29874. 